\title{
Does Realized Skewness Predict the Cross-Section of Equity Returns?
}

Diego Amaya, Peter Christoffersen, Kris Jacobs and Aurelio Vasquez

\section{CREATES Research Paper 2013-41}




\title{
Does Realized Skewness Predict the Cross-Section of Equity Returns?*
}

\author{
Diego Amaya \\ UQAM
}

Kris Jacobs

University of Houston and Tilburg University

\author{
Peter Christoffersen \\ Rotman, CBS and CREATES
}

Aurelio Vasquez

ITAM School of Business

February 21, 2013

\begin{abstract}
We use intraday data to compute weekly realized variance, skewness, and kurtosis for equity returns and study the realized moments' time-series and cross-sectional properties. We investigate if this week's realized moments are informative for the cross-section of next week's stock returns. We find a very strong negative relationship between realized skewness and next week's stock returns. A trading strategy that buys stocks in the lowest realized skewness decile and sells stocks in the highest realized skewness decile generates an average weekly return of 24 basis points with a t-statistic of 3.65. Our results on realized skewness are robust across a wide variety of implementations, sample periods, portfolio weightings, and firm characteristics, and are not captured by the Fama-French and Carhart factors. We find some evidence that the relationship between realized kurtosis and next week's stock returns is positive, but the evidence is not always robust and statistically significant. We do not find a strong relationship between realized volatility and next week's stock returns.
\end{abstract}

JEL Codes: G11, G12, G17

Keywords: Realized volatility; skewness; kurtosis; equity markets; cross-section of stock returns.

${ }^{*}$ We would like to thank Bjorn Eraker, Rene Garcia, Xin Huang, Jia Li, Andrew Patton, Denis Pelletier, George Tauchen, seminar participants at McGill University, Queen's University, Rutgers University, Duke University, Ryerson University, University of British Columbia, Notre Dame University, HKUST, the FMA and EFMA meetings, the $\mathrm{IFM}^{2}$ Mathematical Finance Conference, the Society for Financial Econometrics Conference, Stanford SITE, the Triangle Econometrics Workshop, the Toulouse Financial Econometrics Workshop, and the Market Microstructure Conference in Paris for helpful comments. We thank IFM ${ }^{2}$, SSHRC, and Asociación Mexicana de Cultura A.C. for financial support. Any remaining inadequacies are ours alone. Correspondence to: Peter Christoffersen, Phone: 416-946-5511, Email: peter.christoffersen@rotman.utoronto.ca. 


\section{Introduction}

We examine the properties of higher moments computed from intraday returns. Merton (1980) first noted that volatility can be measured arbitrarily precisely as the sampling frequency increases. This insight was later applied to the measurement of time-varying volatility in the realized volatility literature, which constructs daily measures of realized volatility computed from intraday squared returns. Extending the now well-established concept of realized volatility, we compute realized skewness and kurtosis from intraday cubed and quartic returns. We show that under realistic assumptions, based on a continuous-time specification of equity price dynamics that includes stochastic volatility and jumps, the realized moments converge to the true moments, confirming that Merton's insight applies to skewness and kurtosis. The limits of the higher realized moments are determined by the jump parameters of the continuous-time price process. Using Monte Carlo techniques, we verify that the measurement of the realized higher moments is reliable in finite samples, and that it is robust to the presence of market microstructure noise as well as to quote discontinuities in existence prior to decimalization.

Our empirical strategy uses a very extensive sample of weekly data. We aggregate daily realized moments to obtain weekly realized volatility, skewness, and kurtosis measures for over two million firm-week observations. We find considerable time-variation in the cross-sectional percentiles. While the cross-sectional dispersion in realized volatility has decreased during our sample period, the cross-sectional dispersion for skewness and kurtosis has increased. The median cross-sectional kurtosis has also increased significantly.

Next we examine the relationship between higher moments computed from intraday returns and future stock returns. We sort stocks into deciles based on the current-week realized moment and compute the subsequent one-week return of the trading strategy that buys the portfolio of stocks with a high realized moment (volatility, skewness, or kurtosis) and sells the portfolio of stocks with a low realized moment.

When sorting on realized volatility, the resulting portfolio return differences are not statistically significant. However, when sorting by realized skewness, the long-short value-weighted portfolio produces an average weekly return of -24 basis points with a t-statistic of -3.65 . The resulting four factor Carhart risk adjusted alpha for the long-short skewness portfolio is also close to -24 basis points per week. We find a positive relation between realized kurtosis and subsequent stock returns, but the economic magnitude is smaller and the results are less statistically significant.

We confirm the negative relation between realized skewness and future returns using FamaMacBeth regressions. We also investigate the robustness of these findings when controlling for a number of well-documented determinants of returns: realized volatility and kurtosis, firm size (Fama and French (1993)), the book-to-market ratio (Fama and French (1993)), market beta, lagged return (Jegadeesh (1990), Lehmann (1990) and Gutierrez and Kelley (2008)), historical skewness, idiosyncratic volatility (Ang, Hodrick, Xing, and Zhang (2006)), coskewness, (Harvey and 
Siddique (2000)), maximum return (Bali, Cakici, and Whitelaw (2009)), the number of analysts that follow the firm (Arbel and Strebel (1982)), illiquidity (Amihud (2002)), and the number of intraday transactions. Realized skewness continues to be highly significant in explaining the cross section of returns after controlling for these factors. Two-way sorts on realized skewness and firm characteristics also confirm that the relationship between realized skewness and returns is significant. Finally, results for realized skewness are robust to the January effect and are significant when considering only NYSE stocks. We show that these cross-sectional results also obtain for monthly holding periods.

The positive relation between realized kurtosis and future returns is also confirmed using FamaMacBeth regressions. However, two-way sorts show that the relationship between realized kurtosis and returns is not always significant when controlling for other firm characteristics. Additional robustness exercises confirm that the results for realized kurtosis are not as economically and statistically significant as the results for realized skewness.

To verify that our measures of higher moments are not contaminated by microstructure noise, and to make sure that we are effectively measuring asymmetry and fat tails, we investigate four additional measures of skewness and kurtosis using high frequency data. In the first measure, the return drift is removed from the realized moments. A second measure uses jump-robust estimates of realized volatility to compute higher moments. The third measure is an enhanced version of the realized moment that uses the subsampling methodology suggested by Zhang, Mykland, and Ait-Sahalia (2005) to compute realized volatility. This subsampling methodology ensures that useful data are not ignored and provides a more robust estimator of the realized moment. The fourth approach uses percentiles of the high-frequency return distribution as alternative measures to capture skewness and kurtosis.

We find that the relation between realized kurtosis and stock returns is not always robust to different implementations. However, the negative relation between realized skewness and future stock returns is robust. For our sample, this is not the case for other measures of skewness. Presumably our realized skewness measure provides a simpler and cleaner estimate of skewness, which therefore leads to economically and statistically strong results.

Ang, Hodrick, Xing, and Zhang (2006) find that stocks with high idiosyncratic volatility earn low returns. Motivated by their findings, we further explore the relationship between realized skewness, idiosyncratic volatility and subsequent stock returns. We find that when idiosyncratic volatility increases, low skewness stocks are compensated with higher returns while high skewness stocks are compensated with lower returns. This pattern is stronger for small stocks. Therefore, skewness provides a partial explanation of the idiosyncratic volatility puzzle. We also show that similar findings obtain when using realized volatility instead of idiosyncratic volatility.

Our results build on the voluminous econometric literature on realized volatility, which is succinctly surveyed in Andersen and Benzoni (2009). Schwert (1989) and Paye (2012) use daily returns to construct monthly and quarterly realized volatility and investigate economic drivers of the sec- 
ular variation in market volatility. Hsieh (1991) contains perhaps the first application of realized volatility in finance using intraday data, and Andersen, Bollerslev, Diebold, and Ebens (2001) are among the first to the study realized volatility of individual equities. Fleming, Kirby, and Ostdiek (2003) are the first to apply realized volatility and correlation from intraday data in portfolio allo-

cation. Recently, Bollerslev, Osterrieder, Sizova, and Tauchen (2012) have used realized volatility to asses the risk-return relationship and to forecast future market returns, and Corsi, Fusari, and La Vecchia (2013) use realized volatility to develop a new class of option valuation models. Our paper is the first to exploit the information in high-frequency data to compute firm-level realized skewness and kurtosis as well as realized volatility. We also use these measures in a large-scale analysis of the cross-section of equity returns, using a cross-section of more than two thousand firms each week during our fifteen-year sample.

The remainder of the paper is organized as follows. Section 2 estimates the weekly realized higher moments from intraday returns and constructs portfolios based on these moments. It also investigates the limiting properties of the realized higher moments. Section 3 computes raw and risk-adjusted returns on portfolios sorted on realized volatility, skewness, and kurtosis, and estimates Fama-MacBeth regressions including various control variables. Section 4 contains a series of robustness checks. Section 5 further explores the results by investigating double sorts on higher moments and other firm characteristics, documenting the interaction of volatility, skewness, and returns, and discussing the links between our empirical results and extant theoretical and empirical results. Section 6 concludes.

\section{Constructing Moment-Based Portfolios}

In this section we first describe the data. We then show how the realized higher moments are computed and we investigate their limiting properties. Finally, we form portfolios by sorting stocks into deciles based on the weekly realized moments, and then report on the characteristics of these portfolios.

\section{$2.1 \quad$ Data}

We analyze every listed stock in the Trade and Quote (TAQ) database from January 4, 1993 to September 30, 2008. TAQ provides historical tick by tick data for all stocks listed on the New York Stock Exchange, American Stock Exchange, Nasdaq National Market System, and SmallCap issues. Stocks with prices below $\$ 5$ are excluded from the analysis. We record prices every five minutes starting at 9:30 EST and construct five-minute log-returns for the period 9:30 EST to 16:00 EST for a total of 78 daily returns. We construct the five minute grid by using the last recorded price within the preceding five-minute period. If there is no price in a period, the return for that period is set to zero.

To ensure sufficient liquidity, we require that a stock has at least 80 daily transactions to 
construct a daily measure of realized moments. ${ }^{1}$ The average number of intraday transactions per day for a stock is over one thousand. The weekly realized moment estimator is the average of the available daily estimators (Wednesday through Tuesday). Only one valid day of the realized moment is required to have a weekly estimator.

We use data from three additional databases. From the Center for Research and Security Prices (CRSP) database, we use daily returns of each firm to calculate weekly returns (from Tuesday close to Tuesday close), historical equity skewness, market beta, lagged return, idiosyncratic volatility, maximum return over the previous week and month, and illiquidity; we use monthly returns to compute coskewness as in Harvey and Siddique $(2000) ;^{2}$ we use daily volume to compute illiquidity; and we use outstanding shares and stock prices to compute market capitalization. COMPUSTAT is used to extract the Standard and Poor's issuer credit ratings and book values to calculate book-tomarket ratios of individual firms. From Thomson Returns Institutional Brokers Estimate System (I/B/E/S), we obtain the number of analysts that follow each individual firm. These variables are discussed in more detail in Appendix A.

\subsection{Computing Realized Higher Moments}

We first define the intraday log returns for each firm. On day $t$, the $i$ th intraday return is given by

$$
r_{t, i}=p_{t, \frac{i}{N}}-p_{t, \frac{(i-1)}{N}}
$$

where $p$ is the natural logarithm of the price and $N$ is the number of return observations in a trading day. The opening log price on day $t$ is $p_{t, 0}$ and the closing log price on day $t$ is $p_{t, 1}$. We use five-minute returns so that in 6.5 trading hours we have $N=78$.

The well-known daily realized variance (Andersen and Bollerslev (1998) and Andersen, Bollerslev, Diebold and Labys (2003)) is obtained by summing squares of intraday high-frequency returns

$$
\operatorname{RDV}_{\mathrm{Var}}=\sum_{i=1}^{N} r_{t, i}^{2}
$$

As is standard, we do not estimate the mean of the high-frequency return because it is dominated by the variance at this frequency. See Section 4.1 for a robustness check.

Its model-free nature is an appealing characteristic of this volatility measure compared to other estimation methods (see Andersen, Bollerslev, Diebold, and Labys (2001) and Barndorff-Nielsen and Shephard (2002) for details). Moreover, as we will discuss below, realized variance converges to a well-defined quadratic variation limit as the sampling frequency $N$ increases.

Given that we are interested in measuring the asymmetry of the daily return's distribution, we construct a measure of ex-post realized daily skewness based on intraday returns standardized by

\footnotetext{
${ }^{1}$ We repeated the analysis using a minimum of 100, 250 and 500 transactions instead. The results are similar.

${ }^{2}$ Computing co-moments with high-frequency data is not straightforward due to synchronicity problems between stock and index returns.
} 
the realized variance as follows

$$
\operatorname{RDSkew}_{t}=\frac{\sqrt{N} \sum_{i=1}^{N} r_{t, i}^{3}}{R D \operatorname{Var}_{t}^{3 / 2}}
$$

The interpretation of this measure is straightforward: negative values indicate that the stock's return distribution has a left tail that is fatter than the right tail, and positive values indicate the opposite.

We are interested in extremes of the return distribution more generally, and so we also construct a measure of realized daily kurtosis defined by

$$
\operatorname{RDKurt}_{t}=\frac{N \sum_{i=1}^{N} r_{t, i}^{4}}{R D \operatorname{Var}_{t}^{2}}
$$

The limits of the third and fourth moment when the sampling frequency $N$ increases will be analyzed below as well. The scaling of RDskew $w_{t}$ and $R D K u r t_{t}$ by $\sqrt{N}$ and $N$ ensures that their magnitudes correspond to daily skewness and kurtosis.

Our cross-sectional asset pricing analysis below is conducted at the weekly frequency. We therefore construct weekly realized moments from their daily counterparts as follows. If $t$ is a Tuesday then we compute

$$
\begin{aligned}
\text { RVol } & =\left(\frac{252}{5} \sum_{i=0}^{4} \text { RDVar }_{t-i}\right)^{1 / 2} \\
\text { RSkew }_{t} & =\frac{1}{5} \sum_{i=0}^{4} \text { RDSkew }_{t-i}, \\
\text { RKurt }_{t} & =\frac{1}{5} \sum_{i=0}^{4} \text { RDKurt }_{t-i} .
\end{aligned}
$$

Our cross-sectional analysis below is conducted at the weekly frequency and $t$ will therefore denote a week from this point on. Note that, as is standard, we have annualized the realized volatility measure to facilitate the interpretation of results.

We compute the $R V$ ol $_{t}, R S k e w_{t}$, and $R K u r t_{t}$ for more than two million firm-week observations during our January 1993 to September 2008 sample period. Figure 1 summarizes the realized moments. The top-left panel of Figure 1 displays a histogram of the realized volatility measure pooled across firms and weeks. As often found in the realized volatility literature, the unconditional distribution of realized equity volatility is right-skewed. The top-right panel in Figure 1 shows the time-variation in the cross-sectional percentiles using three-month moving averages. The crosssectional dispersion in realized equity volatility is clearly not constant over time and seems to have decreased through our sample period.

The middle-left panel of Figure 1 shows the histogram of realized equity skewness. The skewness distribution is very fat-tailed and strongly peaked around zero. The middle-right panel of Figure 1 shows the time-variation in the cross-sectional skewness percentiles. The cross-sectional dispersion in realized equity skewness has increased through our sample. 
The bottom-left panel of Figure 1 shows the histogram of realized equity kurtosis. Similar to realized volatility, realized kurtosis appears to be approximately log-normally distributed. The vast majority of our sample has a kurtosis above 3, strongly suggesting fat-tailed returns. The bottomright panel of Figure 1 shows that the cross-sectional distribution of realized equity kurtosis has become more disperse over time, matching the result found for realized skewness.

Figure 1 reveals interesting patterns in the cross-sectional distribution of higher moments over time. We attempt to exploit these patterns for cross-sectional equity pricing in Section 3. First, in order to anchor our analysis, we investigate the limiting properties of higher order moments computed from high-frequency data.

\subsection{Limiting Properties of Realized Moments}

The limiting properties of realized variance have been studied in detail in the econometrics literature, however, much less is known about realized skewness and kurtosis. In this section, we therefore investigate the realized moments under the assumption that the underlying continuous time price process follows a jump-diffusion process with stochastic volatility.

Assume that the log-price $p$ of a security evolves according to the stochastic equation

$$
p_{T}=\int_{0}^{T} \mu_{s} d s+\int_{0}^{T} \sigma_{s} d W_{s}+J_{T}
$$

where $\mu$ is a locally bounded predictable drift process, $\sigma$ is a positive càdlàg process, and $J$ is a pure jump process, and where without loss of generality $p_{0}=0$.

Andersen, Bollerslev, Diebold and Labys (2003) show the following general limit result as the sampling frequency $N$ goes to infinity for realized variance from time 0 to $T$

$$
R M(2) \equiv \sum_{i=1}^{N}\left(p_{T \frac{i}{N}}-p_{T \frac{(i-1)}{N}}\right)^{2} \stackrel{\mathcal{P}}{\rightarrow} \int_{0}^{T} \sigma_{s}^{2} d s+\sum_{0<s \leq T}\left(\Delta p_{s}\right)^{2}, \text { as } N \rightarrow \infty .
$$

where $\Delta p_{s}=p_{s}-p_{s-}$ denotes the change in the log-price due to a jump. This limit as the sampling frequency goes to infinity contains two elements: the integrated variance as well as the sum of squared jumps. We see that the simple realized variance based on five minute returns in equation (2) contains both volatility and jumps in the limit.

For the realized third moment, the results in Barndorff-Nielsen, Kinnebrock, and Shephard (2010) and Jacod (2012) can be used to show that

$$
R M(3) \equiv \sum_{i=1}^{N}\left(p_{T \frac{i}{N}}-p_{T \frac{(i-1)}{N}}\right)^{3} \stackrel{\mathcal{P}}{\rightarrow} \sum_{0<s \leq T}\left(\Delta p_{s}\right)^{3}, \text { as } N \rightarrow \infty .
$$

This result is important in two respects: First, it shows that the realized third moment in the limit separates the jump contribution from the continuous contribution to cubic variation and it captures just the jump part. It does not for example capture skewness arising from correlation 
between return and variance innovations (the "leverage" effect). Second, it shows that the sign of the average jump size is captured: Firms with on average positive jumps will have a positive realized third moment and vice versa.

For the realized fourth moment, Barndorff-Nielsen and Shephard (2004) and Jacod (2012) show that

$$
R M(4) \equiv \sum_{i=1}^{N}\left(p_{T \frac{i}{N}}-p_{T \frac{i-1}{N}}\right)^{4} \stackrel{\mathcal{P}}{\rightarrow} \sum_{0<s \leq T}\left(\Delta p_{s}\right)^{4}, \text { as } N \rightarrow \infty .
$$

We see again that the fourth realized moment in the limit captures the jump component but not the continuous component to quartic variation. The continuous component could for example arise from volatility of volatility in the price process. The fourth power in the limit expression of course implies that positive and negative jumps are treated equally so that only the magnitude of jumps is captured, and not their direction.

We conclude from these general results for the third and fourth realized moments that we may expect very different estimates of skewness and kurtosis depending on the frequency of data used to estimate these moments. Skewness estimates from moving windows of daily or weekly data are likely to have different averages than skewness measures constructed from intraday data. This is in sharp contrast to the second moment, where using higher-frequency returns yields more and more efficient estimates of the same population values as first noted by Merton (1980). Thus the sample means of variances estimated using intraday, daily or weekly data should be roughly similar even if they contain increasing levels of noise.

To fix ideas, consider an example where the log price of a security evolves according to the particular affine stochastic differential equation

$$
\begin{aligned}
& d p_{t}=\left(\mu-\frac{1}{2} V_{t}-\bar{\mu}_{J} \lambda\right) d t+\sqrt{V_{t}} d W_{t}^{(1)}+J d N_{t} \\
& d V_{t}=\kappa\left(\theta-V_{t}\right) d t+\sigma \sqrt{V_{t}} d W_{t}^{(2)}
\end{aligned}
$$

where $\mu$ is the drift parameter, $\kappa$ is the mean reversion speed to the long-term volatility mean $\theta$, and $\sigma$ is the diffusion coefficient of the volatility process $V_{t} . W_{t}^{(1)}$ and $W_{t}^{(2)}$ denote two standard Brownian motions with correlation $\rho$, and $N_{t}$ is an independent Poisson process with arrival rate $\lambda$. The jump size $J$ is distributed $N\left(\mu_{J}, \sigma_{J}^{2}\right)$. The value for $\bar{\mu}_{J}$ is set to $\exp \left(\mu_{J}+\sigma_{J}^{2} / 2\right)-1$.

For this process, the limits of the expected value of the realized moments are given by

$$
\begin{aligned}
& I M(2) \equiv \lim _{N \rightarrow \infty} E_{0}[R M(2)]=\theta T-\left(\theta-V_{0}\right) \frac{\left(1-e^{-\kappa T}\right)}{\kappa}+\lambda\left(\mu_{J}^{2}+\sigma_{J}^{2}\right) T \\
& I M(3) \equiv \lim _{N \rightarrow \infty} E_{0}[R M(3)]=\lambda\left(\mu_{J}^{3}+3 \mu_{J} \sigma_{J}^{2}\right) T \\
& I M(4) \equiv \lim _{N \rightarrow \infty} E_{0}[R M(4)]=\lambda\left(\mu_{J}^{4}+6 \mu_{J}^{2} \sigma_{J}^{2}+3 \sigma_{J}^{4}\right) T .
\end{aligned}
$$

This result can be derived using the transform analysis in Duffie, Pan, and Singleton (2000). Appendix B provides the details. 
These results confirm the intuition from the general case. Consistent with equations (9), (10), and (11), while the second moment contains both jump and diffusion parameters, the third and fourth moments depend exclusively on jump parameters. It is important once again to note that whereas realized variance converges to the total quadratic variation of the process, our realized skewness and kurtosis estimates do not converge to the total cubic and quartic variation. Total cubic variation includes diffusive skewness arising for example from the correlation $\rho$ between the two Brownian innovations. Total quartic variation includes diffusive kurtosis arising from volatility of volatility which is captured by the parameter $\sigma$. In the limit, our measures pick up the contribution to skewness and kurtosis from jumps only. Total cubic and quartic variation can only be estimated from long samples of low-frequency returns or by using options to retrieve risk-neutral moments as in Neuberger (2012) and Conrad, Dittmar, and Ghysels (2013) who rely on the methodology in Bakshi, Kapadia, and Madan (2003). The conclusion is once again that skewness (and kurtosis) measures computed from high-frequency data are likely to contain different information from those computed from daily data or from options. We discuss these differences in detail in Section 4.4.

In Appendix $\mathrm{C}$ we provide Monte Carlo evidence on the finite-sample properties of $R M(j)$ in the presence of market microstructure noise and discontinuities in quoted prices. The results show that the finite-sample moment estimates are well behaved. Armed with the knowledge of well-defined limits, as well as the satisfactory finite sample properties of our moment estimates, we are now ready to assess the ability of our realized higher moments to explain the cross-section of equity returns.

\subsection{Portfolio Sort Characteristics}

Each Tuesday, we form portfolios by sorting stocks into deciles based on the weekly realized moments. Table 1 reports the time-series sample averages for the moments and different firm characteristics, by decile. Panel A reports the time-series averages for realized volatility, Panel B for realized skewness, and Panel $\mathrm{C}$ for realized kurtosis. Column 1 contains the portfolio of stocks with the smallest average realized moment, and column 10 contains the portfolio of stocks with the highest realized moment. The characteristics include firm size, book-to-market ratio, realized volatility over the previous week, historical skewness using daily returns from the previous month, market beta from the market model regression, lagged return, illiquidity as in Amihud (2002), coskewness as in Harvey and Siddique (2000), idiosyncratic volatility as in Ang, Hodrick, Xing, and Zhang (2006), the number of analysts from I/B/E/S, credit rating, stock price, the number of intraday transactions, and the number of stocks per decile. On average there are 257 companies per decile each week.

Table 1, Panel A displays results for the ten decile portfolios based on realized volatility. Realized volatility increases from $18.8 \%$ for the first decile to $145.0 \%$ for the highest decile. Interestingly, realized skewness has a negative relation with realized volatility, and realized kurtosis shows an increasing pattern through the volatility deciles. Furthermore, companies with high realized volatility 
tend to be small, followed by fewer analysts, less coskewed with the market, and they have a lower stock price. A positive relation exists between realized volatility and historical skewness, market beta, lagged return, idiosyncratic volatility and maximum monthly return. Finally, no pattern is observed between realized volatility and book-to-market, number of intraday transactions, and credit rating.

Panel B of Table 1 shows that realized skewness equals -1.04 for the first decile portfolio and 1.02 for the tenth decile. Firms with a high degree of asymmetry, either positive or negative, are small, highly illiquid, followed by fewer analysts, and the number of intraday transactions for these firms is lower.

Panel $\mathrm{C}$ of Table 1 reports on the decile portfolios based on realized kurtosis. The average kurtosis ranges from 3.9 to 16.6 across the deciles. Firm characteristics that are positively related to realized kurtosis include realized volatility, historical skewness, lagged return, idiosyncratic volatility, illiquidity and maximum monthly return. Variables that have a negative relation with realized kurtosis include size, market beta, coskewness, number of I/B/E/S analysts, stock price, and number of intraday transactions.

In summary, Table 1 strongly suggests that firm-specific realized volatility, skewness, and kurtosis all contain unique information about the cross-sectional distribution of equity returns.

Figure 2 complements Table 1 by reporting the time series of realized higher moments by firm size (Panel A), book to market (Panel B), and market beta (Panel C). For each moment we plot the average value for each of the terciles using 3-month moving averages as in Figure 1. Figure 2 clearly shows that the variation in realized volatility (left column) and realized kurtosis (right column) is robustly related to the cross-sectional variation in size, book to market, and market beta. Over time, realized volatility tends to be consistently highest for firms with small market caps, low book to market and high market betas. Realized kurtosis tends to be consistently high for small caps, high book to market firms, and low beta firms. While these general patterns may not generally be surprising, the high and increasing realized kurtosis for low beta firms is perhaps not expected. It may partly explain the high rewards for holding low beta stocks as recently documented by Frazzini and Pedersen (2012). The change in the cross-sectional distribution of realized volatility by market capitalization in the top left panel is interesting as well. In the early part of the sample the volatility of small caps is roughly five times that of large caps, whereas at the end of the sample their volatility levels are almost identical.

In sharp contrast to volatility and kurtosis, the variation in skewness seems largely unrelated to the three well-known determinants of returns studied in Figure 2. These results suggest that skewness may have the most potential of the three moments to serve as a new independent driver of variation in expected return in the cross section. This is the topic to which we now turn. 


\section{Realized Moments and the Cross-Section of Stock Returns}

In this section, we first analyze the relationship between the current week's returns and the previous week's realized volatility, realized skewness, and realized kurtosis. Subsequently, we use the Fama and MacBeth (1973) methodology to conduct cross-sectional regressions, and to determine the significance of each higher realized moment individually and simultaneously. We also use these cross-sectional regressions to control for other firm-specific determinants of returns.

\subsection{Sorting Stock Returns on Realized Volatility}

Every Tuesday, stocks are ranked into deciles according to their realized volatility. Then, using returns over the following week, we construct value- and equal-weighted portfolios. Table 2, Panel A reports the time series average of weekly returns for decile portfolios based on the level of realized volatility.

The value-weighted returns decrease from 20 basis points for decile 1 to 8 basis points for decile 10. On the other hand, equal-weighted returns increase from 22 basis points to 27 basis points. Thus, the returns of the long-short portfolio, namely one that buys stocks in decile 10 and sells stocks in decile 1, are negative for value-weighted portfolios and positive for equal-weighted ones. The negative relation between individual volatility and stock returns for value-weighted portfolios is consistent with Ang, Hodrick, Xing, and Zhang (2006). However, neither the value-weighted nor the equal-weighted long-short portfolios are statistically significant, and this is the case for raw returns as well as for alphas from the Carhart four factor model. The four factor model employs the three Fama and French (1993) factors (excess market-return, size and book-to-market) and the Carhart (1997) momentum factor.

We conclude that in our sample, realized volatility and next week's stock returns are not robustly related when using our measure of realized volatility.

\subsection{Sorting Stock Returns on Realized Skewness}

Table 2, Panel B reports the time-series average of weekly returns for decile portfolios grouped by realized skewness.

The value-weighted and equal-weighted returns both show a decreasing pattern between realized skewness and the average stock returns over the subsequent week. The return for the portfolio of stocks with the lowest level of skewness is 40 basis points for value-weighted portfolios and 55 basis points for equal-weighted portfolios, while the returns for stocks with the highest level of realized skewness is 17 basis points for value-weighted and 12 for equal-weighted portfolios. The weekly return difference between portfolios 10 and 1 is -24 basis points for value-weighted returns and -43 for equal-weighted returns. Both differences are statistically significant at the one percent level. This result is consistent with recent theories stating that stocks with lower skewness command a risk premium. For prominent examples, see Barberis and Huang (2008) and Mitton and Vorkink 
(2007). The equal-weighted return difference is larger than the value-weighted return difference, suggesting that the relationship between skewness and subsequent returns is larger for small firms.

We also assess the empirical relationship between realized skewness and stock returns by adjusting for standard measures of risk. Panel B of Table 2 presents, for each decile, alphas relative to the Carhart four factor model. Note that alphas are large and statistically significant for value- and equal-weighted portfolios across deciles. In addition, the difference between the alphas of the tenth and first deciles is -24 and -44 basis points for value- and equal-weighted portfolios, respectively. Most alphas are estimated to be positive, which may reflect transaction costs (Lesmond, Ogden, and Trzcinka (1999)) or the construction of the factors (Cremers, Petajisto, and Zitzewitz (2010)).

Our long-short skewness returns are also large when compared with the standard four factor returns. In our sample the weekly return on the market factor is 12 basis points per week, the size factor return is 2 basis points, the value factor return is 10 basis points, and momentum yields 20 basis points per week on average.

In conclusion, we find strong evidence of a negative cross-sectional relationship between realized skewness and future stock returns. Realized skewness is an important determinant of the crosssectional variation in subsequent one-week returns, and its effect is not captured by standard measures of risk.

\subsection{Sorting Stock Returns on Realized Kurtosis}

Panel C of Table 2 documents the average next-week stock returns for decile portfolios based on realized kurtosis. Value-weighted and equal-weighted portfolio returns both increase with the level of realized kurtosis. For value weighted portfolios, decile 1 has an average weekly return of 17 basis points, compared to 31 basis points for decile 10. Thus, the long-short portfolio generates a return of 14 basis points with a t-statistic of 2.12. A similar result is found for the equal-weighted portfolio, where the long-short realized kurtosis premium equals 16 basis points with a t-statistic of 2.98 .

The estimates for the Carhart four-factor alpha are smaller and less statistically significant compared to those for the raw returns. The value-weighted alpha for the long-short portfolio is 7 basis points and the equal-weighted alpha is 8 basis points. The equal-weighted alpha is significant at the $5 \%$ level, while the value-weighted alpha is not significant.

Comparing Panels A, B, and C of Table 2, we conclude that, while the evidence suggests a positive relation between realized kurtosis and returns, realized skewness appears to be the most reliable moment-based indicator of subsequent one-week equity returns in the cross section.

\subsection{Fama-MacBeth Regressions}

To further assess the relationship between future returns and realized volatility, realized skewness, and realized kurtosis, we carry out various cross-sectional regressions using the method proposed in 
Fama and MacBeth (1973). Each week $t$, we compute the realized moments for firm $i$ and estimate the following cross-sectional regression:

$$
r_{i, t+1}=\gamma_{0, t}+\gamma_{1, t} R V \operatorname{Vol}_{i, t}+\gamma_{2, t} R_{S k e w_{i, t}}+\gamma_{3, t} \text { RKurt }_{i, t}+\phi_{t}^{\prime} Z_{i, t}+\varepsilon_{i, t+1}
$$

where $r_{i, t+1}$ is the weekly return (in bps) of the $i$ th stock for week $t+1$, and where $Z_{i, t}$ represents a vector of characteristics and controls for the $i$ th firm observed at the end of week $t$. The characteristics and controls included are firm size, book-to-market, market beta, lagged return, historical skewness, idiosyncratic volatility, coskewness, maximum monthly return (in bps), maximum weekly return (in bps), number of analysts, illiquidity, and number of intraday transactions.

Table 3 reports the time-series average of the $\gamma$ and $\phi$ coefficients for five cross-sectional regressions. The first column presents the results of the regression of the stock return on lagged realized volatility. The coefficient associated with realized volatility is 5.9 with a Newey-West t-statistic of 0.43. This confirms that there does not seem to be a significant relationship between realized volatility and stock returns. The second and third columns confirm the relation between the stock return and lagged realized skewness and realized kurtosis respectively. In column 2 , the coefficient associated with realized skewness is -22.4 with a Newey-West t-statistic of -7.92 . Similarly, in column 3, the coefficient on realized kurtosis is 1.25 with a t-statistic of 3.39. In the fourth column, we report regression results using all higher moments simultaneously. The coefficients on lagged realized skewness and realized kurtosis remain statistically significant, and are again negative and positive respectively. The third and fourth realized moments appear to explain different aspects of stock returns.

In the last column, we add the control variables to ensure that realized skewness and realized kurtosis are not a manifestation of previously documented relationships between firm characteristics and stock returns. Some control variables are related to the illiquidity and visibility of individual stocks. This includes the number of intraday transactions, the measure of illiquidity proposed in Amihud (2002), and the number of analysts following a stock (see Arbel and Strebel (1982)). We also control for the previously documented relationships between stock returns and firm characteristics, such as idiosyncratic volatility (Ang, Hodrick, Xing, and Zhang (2006)), the maximum daily return over the previous month (Bali, Cakici, and Whitelaw (2009)), lagged weekly return (Lehmann (1990)), and the stock's coskewness as measured by the variability of the stock's return with respect to changes in the level of volatility following Harvey and Siddique (2000). Because our data are weekly, we also include the maximum daily return over the previous week as a robustness check. Finally, we control for the market beta computed with a regression using daily returns on the market over the previous 12 months.

We find that the coefficients of realized skewness and realized kurtosis are still significant when including the control variables in the last column of Table 3, with Newey-West t-statistics of -6.90 and 1.91, and preserve their signs with coefficients of -12.7 and 0.61 , respectively. The absolute 
value of the point estimates is smaller for both skewness and kurtosis compared to columns (2)-(4), suggesting that some of the cross-sectional patterns documented in Table 2 overlap with some of the control variables.

Table 3 indicates that control variables such as realized volatility, idiosyncratic volatility, and coskewness do not play a significant role in the cross-section of returns at a weekly level, while variables such as size, lagged return, and maximum return are relevant. The negative sign on the coefficients related to size and lagged return and the positive sign of the coefficient related to book-to-market confirm existing results in the literature.

In summary, Table 3 demonstrates that the economic and statistical significance of realized skewness for the cross-section of weekly returns is robust to the inclusion of various control variables. Table 3 is also supportive of the relation between realized kurtosis and subsequent returns. The estimated sign on realized kurtosis is consistent with the evidence in Table 2, but the results in Table 3 are stronger. This is not necessarily surprising: sorts as in Table 2 are more intuitive, but the more formal regressions in Table 3 capture linear relationships better.

\section{Robustness Analysis}

In this section, we further explore the relation between realized moments and stock returns. First, we investigate the relation between current-week realized moments and next-week returns for driftadjusted realized moments. Second, we investigate if our findings on skewness and kurtosis continue to hold up when using jump-robust realized volatility estimators. Third, we investigate alternative measures of realized skewness. Fourth, we further investigate historical skewness estimated on daily returns. Fifth, we look at long-short returns for different subsets of our data. Sixth, we use monthly rather than weekly holding periods for returns.

\subsection{Drift-Adjusted Realized Moments}

The computation of daily realized volatility, realized skewness, and realized kurtosis in equations (2), (3) and (4) assumes that the 5-minute mean return is zero. This is a standard assumption for such short time intervals. However, because the resulting skewness measure may capture the reversal effect, it is imperative to check if our results are robust to changing this assumption. To ensure that our measures are not contaminated by the weekly return, we define the following daily realized measures adjusted for the drift: 


$$
\begin{aligned}
\text { DriftRDVar }_{t} & =\sum_{i=1}^{N}\left(r_{t, i}-\mu_{w(t), i}\right)^{2}, \\
\text { DriftRDSkew }_{t} & =\frac{\sqrt{N} \sum_{i=1}^{N}\left(r_{t, i}-\mu_{w(t), i}\right)^{3}}{\operatorname{DriftRDVar}_{t}^{3 / 2}}, \\
\text { DriftRDKurt }_{t} & =\frac{N \sum_{i=1}^{N}\left(r_{t, i}-\mu_{w(t), i}\right)^{4}}{\operatorname{DriftRDVar} \operatorname{Vr}_{t}^{2}},
\end{aligned}
$$

The notation $\mu_{w(t), i}$ reflects that for any given day $t$ in a given week and for any stock $i$, the average return for that day (scaled to 5 minutes) is computed using all days in that week, to obtain more precise estimates. The weekly realized moments, $R V$ ol $_{d r i f t}, R S k e w_{d r i f t}, R K$ urt $_{d r i f t}$, are then computed using equations (5), (6) and (7) with the drift-adjusted daily moments.

Panel A of Table 4 reports the time-series average of weekly returns for decile portfolios grouped by $R$ Skew $w_{\text {drift }}$. The equal- and value- weighted long-short returns are negative and statistically significant. The value weighted long-short return is -14.10 basis points with a t-statistic of -2.51 . Equal-weighted long-short returns are larger. The Carhart four factor long-short alphas are very similar to the long-short raw return.

Panel B of Table 4 reports the time-series average of weekly returns for decile portfolios grouped

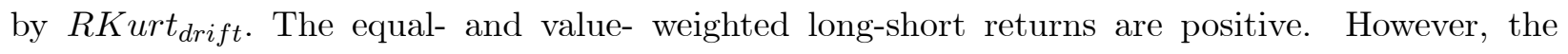
Carhart four factor long-short alpha is not significant for value-weighted returns. We do not report on $R V$ ol $_{\text {drift }}$ because the results are very similar to Table 2 and therefore inconclusive.

We also run the two-step Fama-MacBeth regressions using the drift-adjusted moments. Table 5 repeats the five regressions of Table 3 with the drift-adjusted realized moments. In columns (1)-(3), we run the univariate regressions for the new realized volatility, skewness, and kurtosis measures. In column (4), we use the three moments jointly. Finally, column (5) includes all the control variables used in Table 3. The coefficients on the drift adjusted realized skewness are negative and highly statistically significant in all regressions. Similarly, the coefficients for realized kurtosis adjusted by drift are positive and statistically significant in all regressions.

\subsection{Higher Moments with Jump-Robust Realized Volatility Estimators}

For the class of affine jump-diffusion models often considered in the volatility literature, the limit of the sum of intraday squared returns in (2) can be written as the sum of jump variation and integrated variance. The realized variance estimator used in the empirics so far therefore captures both jumps and diffusive volatility in the limit. This does not invalidate it as an ex-post measure for the total daily quadratic variation, but it does suggest a robustness exercise using measures that separate jump variation and integrated variance.

Several volatility estimators that are robust to the presence of jumps have been developed in the literature. They are designed to only capture integrated variance in the limit. The so-called 
bipower variation estimator of Barndorff-Nielsen and Shephard (2004) is defined by

$$
B P V_{t}=\frac{\pi}{2} \frac{N}{N-1} \sum_{i=1}^{N-1}\left|r_{t, i+1}\right|\left|r_{t, i}\right|
$$

which converges in the limit to integrated variance, even in the presence of jumps.

Motivated by the presence of large jumps that may bias upward the bipower variation measure in realistic settings when $N$ is finite, Andersen, Dobrev and Schaumburg (2010) have recently developed two alternative jump-robust estimators, defined by

$$
\begin{aligned}
\operatorname{MinRV}_{t} & =\frac{\pi}{\pi-2}\left(\frac{N}{N-1}\right) \sum_{i=1}^{N-1} \min \left\{\left|r_{t, i}\right|,\left|r_{t, i+1}\right|\right\}^{2}, \text { and } \\
M e d R V_{t} & =\frac{\pi}{6-4 \sqrt{3}+\pi}\left(\frac{N}{N-2}\right) \sum_{i=2}^{N-1} \operatorname{median}\left\{\left|r_{t, i-1}\right|,\left|r_{t, i}\right|,\left|r_{t, i+1}\right|\right\}^{2} .
\end{aligned}
$$

These estimators will also both converge to the integrated variance when $N$ goes to infinity and in the presence of large jumps they typically have better finite sample properties than $B P V_{t}$.

To assess the robustness of our cross-sectional return results, Table 6 reports the value-weighted and equal-weighted weekly returns of the difference between portfolio 10 (highest realized moment) and portfolio 1 (lowest realized moment) when using the three alternative realized volatility estimators, $B P V_{t}, M i n R V_{t}$, and $M e d R V_{t}$. To facilitate comparisons, the first column of Table 6 uses the standard $R V$ ol $_{t}$ from (5) and thus reproduces the last column of Table 2. Each panel in Table 6 reports the value-weighted and the equal-weighted long-short returns. Alpha is again computed using the Carhart four factor model.

Panel A in Table 6 reports the long-short results for the three alternative realized volatility estimators. We find that the insignificant relationship between return and volatility remains when alternative estimators of realized volatility are used.

Panel B in Table 6 shows the long-short results for realized skewness when scaling by the three alternative realized volatility estimators. We see that the strong negative relationship between realized skewness and returns found in Table 2 is robust to changing the denominator in

$$
R D S k e w_{t}=\frac{\sqrt{N} \sum_{i=1}^{N} r_{t, i}^{3}}{R D V a r_{t}^{3 / 2}}
$$

to be any of the three jump-robust volatility estimators defined in this section.

Panel $\mathrm{C}$ in Table 6 presents results for realized kurtosis when scaling by the three alternative realized volatility estimators. Point estimates for the long-short returns and alphas are positive, but results for value-weighted alphas are not statistically significant.

We conclude that the strong negative relationship between realized skewness and subsequent returns in the cross-section is not an artefact of a particular measure of realized volatility. The 
results hold up when we use estimators of realized volatility that are jump-robust. Consistent with our other findings, the results for realized kurtosis are less robust, even though the overall evidence suggests a positive relationship.

\subsection{Alternative Measures of Realized Skewness}

We now investigate the robustness with respect to the implementation of realized skewness by analyzing two alternative estimators. The first estimator, SubRSkew, uses the subsampling methodology suggested by Zhang, Mykland, and Ait-Sahalia (2005), which provides measures robust to microstructure noise. This method consists of constructing subsamples that are spaced every 5 minutes. Instead of one realized measure based on a single five-minute return grid, we thus have six estimators of realized skewness using subsamples of 30-minute returns for the period 9:30 EST to 16:00 EST. Subsamples start every five minutes (at 9:00, 9:05, 9:10, 9:15, 9:20 and 9:25), but employ 30-minute returns. Subsequently, the realized skewness estimator is computed as the average of the six (overlapping) estimators obtained from the subsamples. Additionally, we compute SubRSkew $w_{\text {drift }}$ using the subsampling methodology on the drift adjusted realized measures described in the previous section.

The second alternative estimator of intraday skewness depends solely on quartiles from the intraday return distribution. As proposed in Bowley (1920), a measure of skewness that is based on quartiles can be defined as

$$
S K 2_{t}=\left(Q_{3}+Q_{1}-2 Q_{2}\right) /\left(Q_{3}-Q_{2}\right)
$$

where $Q_{i}$ is the $i^{\text {th }}$ quartile of the five-minute return distribution.

Panel A of Table 7 includes our results for RSkew from Table 2, as well as results for the estimators SubRSkew and SubRSkew drift which are based on the subsampling methodology suggested by Zhang, Mykland, and Ait-Sahalia (2005), and for the $S K 2$ measure based on quartiles in (22). We also include simple historical skewness computed using daily returns over different horizons. The problem with computing historical skewness from daily returns is well-known: one needs a

sufficiently long window to capture outliers that identify skewness, but longer windows may lead to artificial smoothness in the resulting skewness series. We report results for five-days, one-month, six-months, one-year, two-year, and five-year historical skewness.

Panel A of Table 7 documents statistically significant negative value-weighted long-short returns for the alternative measures $S u b R S k e w, S u b R S k e w_{d r i f t}$, and $S K 2$. The long-short return is smaller for the $S K 2$ and SubRSkewdrift measures, but it is much larger for SubRSkew compared with the RSkew measure. The subsampling skewness measure, SubRSkew, has a long-short raw valueweighted return of -47 basis points and a Carhart alpha of -51 basis points with t-statistics of -5.80 and -6.38 . The subsampling skewness adjusted by drift has a premium of -18 basis points with a t-statistic of -2.74 and a Carhart alpha of -22 basis points with a t-statistic of -3.24 . 
We conclude that all measures of realized skewness yield statistically significant negative longshort alphas.

\subsection{Low Frequency Measures of Skewness}

In this section we investigate the cross-sectional pricing of historical skewness computed from daily returns. This is not a robustness check per se, but rather an investigation of the differential information on skewness in high-frequency versus daily data.

We compute six different measures of historical skewness using daily data: $H S k e w_{5 D}$ uses a moving window of five trading days to compute skewness, HSkew $1 M$ uses one month of daily data, etc. The longest window is used in $H S k e w_{60 M}$, which uses 60 months of daily data. The six measures of historical skewness in Panel B of Table 7 yield very different results from the realized skewness measures in Panel A: Using five-days and one-month windows, long-short returns and alphas are positive and statistically significant, consistent with the coefficient on historical skewness in Table 3, which is obtained using one month of daily data. For the other four measures, results are usually not statistically significant. Only the 60-month window yields negative (but not significant) long-short returns and alphas. In summary, we find that the value-weighted results for historical skewness critically depend on the window used to compute skewness. The equal-weighted returns yield more negative long-short returns. We only get a statistically significant negative alpha when using a sixty-month window.

Contrasting Panel B with Panel A in Table 7 highlights the importance of the limiting results from Section 2.3: Skewness measures computed from high-frequency data capture jumps and contain different information from skewness measures computed from daily data. It is therefore not surprising that the return premia from sorting stocks on low-frequency HSkew measures yield are different from the return premia from sorting stocks on high-frequency RSkew measures. These results suggest a need for asset pricing models with differential risk premia on the diffusive and jump components of skewness.

Zhang (2006) measures the skewness for a given firm by the cross-sectional skewness of the firms in that industry. Boyer, Mitton, and Vorkink (2010) construct a measure of expected idiosyncratic skewness that controls for firm characteristics. We performed an elaborate robustness analysis with respect to the implementation of the measures proposed by Zhang (2006) and Boyer, Mitton, and Vorkink (2010). When we use the implementation by Boyer, Mitton, and Vorkink (2010), we obtain a statistically significant negative relationship in our sample. However, we find that just as with historical skewness, results depend critically on the windows used in estimation. For our sample the skewness measure proposed by Zhang (2006) yields a negative relationship, but it is not statistically significant. 


\subsection{Subsamples}

Panel A of Table 8 reports value- and equal-weighted returns of portfolios sorted on realized skewness across different subsamples. Keim (1983) documents calendar-related anomalies for the month of January, in which stocks have higher returns than in the rest of the year. Panel A of Table 8 presents the average weekly returns for the month of January and for the rest of the year for both value- and equal-weighted portfolios. As expected, returns for the month of January are consistently higher than returns for the rest of the year.

The difference between the returns of portfolios with high-skewness stocks and portfolios with low-skewness stocks is negative and significant for both January and non-January periods. This is the case for value-weighted as well as equal-weighted portfolios.

We previously documented that stocks with high and low levels of skewness tend to be small. Hence, we examine if the effect of skewness is exclusively driven by small NASDAQ stocks. By only including stocks from the New York Stock Exchange (NYSE), row 3 of Table 8 shows that the effect of realized skewness is present among NYSE stocks. Hence, small NASDAQ stocks are not driving our results.

In Table 8, Panel B, we analyze the value-weighted and equal-weighted returns of portfolios sorted on realized kurtosis for different subsamples. The long-short portfolio returns are positive for all subsamples. As expected, in January the long-short portfolio earns higher returns compared to the rest of the year. We also confirm that the effect of realized kurtosis is not driven by small NASDAQ stocks. For value-weighted portfolios the realized kurtosis premium is positive, but often not statistically significant, again indicating that the cross-sectional relationship between realized kurtosis and future returns is less robust than the one documented for realized skewness.

We omit results for realized volatility across subsamples because they confirm the results of Table 2, and we do not find a robust pattern.

\subsection{Monthly Returns}

Thus far our empirics have been based on weekly returns and weekly realized moments. In this section we keep the weekly frequency when computing realized moments but we increase the return holding period from one week to one month.

Table 9 contains the results for overlapping monthly returns. As for the weekly returns in Table 2, we report the returns of decile portfolios formed from realized moments, and the return difference between portfolio 10 (highest realized moment) and portfolio 1 (lowest realized moment). Each panel reports on both value-weighted and equal-weighted portfolios and include t-statistics computed from robust standard errors. Alpha is again computed using the Carhart four factor model.

The strong negative relationship between realized skewness and returns in Table 2 is confirmed when using monthly returns. This relationship is significant for raw returns as well as alphas, and 
for value-weighted and equal-weighted portfolios.

We repeat this analysis for realized volatility and kurtosis. Volatility yields a negative sign and kurtosis a positive sign. The results for volatility are not statistically significant, and kurtosis yields significant results for returns but not for alphas. Again we do not report these results to save space; they are available on request.

\section{$5 \quad$ Exploring the Results}

In this section, we further analyze the interaction between realized moments and other firm characteristics using double sorts. Subsequently we pay special attention to the interaction between realized skewness, realized volatility, and the cross-section of returns. Finally, we relate our results to the existing empirical and theoretical literature.

\subsection{Realized Moments and Firm Characteristics}

This section further analyzes the interaction between realized moments and other firm characteristics. Consider size as an example. While anomalies for small firms may be interesting, Fama and French (2008) point out that to ensure the general validity of an anomaly, small (microcaps), medium, and large firms ought to all exhibit the anomaly. We use an independent double sorting methodology to analyze the realized skewness premium and the realized kurtosis premium for five different size portfolios. We sort stocks into quintiles by size and by realized skewness. Using the intersection of both characteristics, we compute value- and equal-weighted returns for the resulting twenty-five portfolios. Row 1 of Table 10 reports the return from being long the highest skew portfolio and short the lowest skew portfolio conditional on different firm size. This methodology yields a realized skewness premium conditional on size, and allows us to assess if the realized skewness premium is economically significant for all size levels. We also provide a similar analysis for the following firm characteristics: market beta, lagged return, BE/ME, realized volatility, historical skewness, illiquidity, number of intraday transactions, maximum return over the previous month, number of I/B/E/S analysts, idiosyncratic volatility, and coskewness.

Again using size in row 1 as an example, the realized skewness value-weighted premium of -75 basis points for quintile 1 can be earned by buying small stocks (microcaps) with high realized skewness and selling small stocks with low realized skewness. For big firms in quintile 5, the corresponding premium is -29 basis points. All five size groups exhibit the realized skewness anomaly, but the premium is larger for small stocks. This finding explains why the effect of realized skewness is weaker for value-weighted portfolios when compared to equal-weighted portfolios, as evident in Table 2. The stronger negative effect of skewness for small firms is also consistent with Chan, Chen, and Hsieh (1985), who show that there are risk differences between small and large firms. The realized skewness premium and t-statistics are of similar magnitude for equal-weighted returns. 
According to Fama and French's criterion, the evidence in favor of the skewness premium is overwhelming. Table 10 indicates that the realized skewness premiums are negative in all but one case, and statistically significant for almost all cases, for value-weighted and equal-weighted portfolios. The relationship between realized skewness and subsequent returns is robust to all firm characteristics and is not a proxy for any of them.

We also performed a double sort on realized kurtosis and firm characteristics. The results indicate that while the long-short return is positive in the large majority of cases, the results are not as strong as for skewness in Table 10. This confirms our other findings, and we therefore do not report the results to save space. They are available on request.

\subsection{Realized Skewness and Realized Volatility}

We now further examine the interaction between the effects of realized skewness and realized volatility on returns. We construct portfolios using a double sort on realized skewness and realized volatility and then examine subsequent stock returns. First, we form five quintile portfolios with different levels of realized skewness. Within each of these portfolios, we form five portfolios that have different levels of realized volatility. ${ }^{3}$ Panel A of Figure 3 shows the value- and equal-weighted returns for the 25 portfolios double sorted on realized skewness and realized volatility. The variation in the moments across portfolios is large. Realized skewness increases from -0.772 to +0.762 and realized volatility increases from $20 \%$ to about $120 \%$ across portfolios. Equal-weighted portfolios with low realized volatility of $20 \%$ have very similar returns for all five levels of realized skewness, between 20 and 30 basis points. However, as realized volatility increases, the return of low and high realized skewness portfolios strongly diverges. Portfolios with high realized volatility of $120 \%$ report the highest and the lowest return of all 25 portfolios. Stocks with the lowest realized skewness earn the highest average equal-weighted return of 77 basis points, and stocks with the highest realized skewness earn the lowest average return of -9 basis points. For value-weighted portfolios, similar conclusions obtain, but Panel A of Figure 3 indicates that the differences between portfolios are smaller. The nature of the relation between realized skewness, realized volatility, and returns is therefore clearly size-dependent.

Our findings are consistent with the mechanics of the equilibrium model in Colacito, Ghysels, and Meng (2012), which contains an interaction between second and third moments. As positive asymmetry increases, volatility is welfare increasing as it implies a larger probability of an extremely good state of the economy. The opposite is true for the case of negative skewness, since higher volatility increases the likelihood of a left tail event.

We conclude that it is important to account for skewness when analyzing the return/volatility relationship. Highly volatile stocks may earn low returns, which seems counterintuitive, but the reason is that their skewness is high, especially for small stocks. ${ }^{4}$

\footnotetext{
${ }^{3}$ Sorting on realized volatility first, and subsequently on realized skewness, does not change the results.

${ }^{4}$ This finding is supported by Golec and Tamarkin (1998), who show that gamblers at horse races accept bets with
} 


\subsection{Realized Skewness and Idiosyncratic Volatility}

Building on our findings regarding volatility and skewness, we now investigate whether realized skewness can explain the idiosyncratic volatility puzzle uncovered by Ang, Hodrick, Xing, and Zhang (2006). They find that stocks with high idiosyncratic volatility earn lower returns than stocks with low idiosyncratic volatility, contradicting the implications of mean-variance models. We first replicate the results for the idiosyncratic volatility puzzle in Ang, Hodrick, Xing, and Zhang (2006) for our sample. We do not report the detailed results, they are available on request. For value-weighted portfolios, we find a weekly premium of $-0.24 \%$ with a t-statistic of -1.73 for the period 1993-2008. This result is comparable to that of Ang, Hodrick, Xing, and Zhang (2006) who find a monthly premium of $-1.06 \%$ with a t-statistic of -3.10 for the period $1963-2000$. We also obtain negative estimates for equal-weighted portfolios, but the results are not statistically significant.

To study the interaction between realized skewness and idiosyncratic volatility on stock returns we employ double sorting. Panel B of Figure 3 shows the returns of the 25 equal-weighted portfolios for different levels of idiosyncratic volatility. Just as with realized volatility in Panel A of Figure 3 , high idiosyncratic volatility is compensated with high returns only if skewness is low. Investors are willing to accept low returns and high idiosyncratic volatility in exchange for high positive skewness. For value-weighted portfolios, the pattern is less prominent.

These results suggest that investors may trade high idiosyncratic volatility and low returns for high skewness, because they like positive skewness. Preference for skewness may explain some aspects of the idiosyncratic volatility puzzle, but this explanation is clearly related to firm size.

\subsection{Further Discussion}

We now discuss the relationship between our empirical results and the extant theoretical and empirical literature in more detail.

The theoretical relationship between higher moments and stock returns has been a topic of study since Kraus and Litzenberger (1976), who show theoretically that coskewness is a determinant of the cross-section of stock returns. Going beyond co-moments, different types of theoretical arguments suggest that assets' (idiosyncratic) skewness may explain asset returns. Barberis and Huang (2008) demonstrate that assets with greater skewness have lower returns when investors make decisions according to cumulative prospect theory. Mitton and Vorkink (2007) obtain a similar result for expected skewness when investor preferences for skewness are heterogeneous. Both papers predict a negative relationship between an asset's skewness and its return. ${ }^{5}$ To the best of our knowledge no such theoretical results are available for kurtosis. ${ }^{6}$

low returns and high volatility only because they enjoy the high positive skewness offered by these bets.

${ }^{5}$ The optimal expectations framework of Brunnermeier, Gollier, and Parker (2007) also predicts a relationship between skewness and returns, but the sign can be positive or negative dependent on how investors under- or overweigh the tails.

${ }^{6}$ Dittmar (2002) establishes decreasing absolute prudence as a condition for a positive premium for co-kurtosis, 
Our empirical results on realized skewness are consistent with theory and with the empirical results in Boyer, Mitton, and Vorkink (2010), who find that stocks with higher expected idiosyncratic skewness yield lower future returns. Grouping stocks by industry, Zhang (2006) documents a negative relation between skewness and stock returns. Skewness measures extracted from options yield contradictory results on the relation between option implied skewness and future returns in the cross-section. While Xing, Zhang, and Zhao (2010) and Rehman and Vilkov (2010) document a positive relation, Conrad, Dittmar, and Ghysels (2013) find a negative one. As for kurtosis, Conrad, Dittmar, and Ghysels (2013) report that risk-neutral kurtosis and stock returns are positively related. ${ }^{7}$

In our benchmark results in Table 2, the long-short value-weighted portfolio sorted on realized skewness produces an average weekly return and four factor Carhart risk adjusted alpha of -24 basis points. This exceeds the premiums reported in Boyer, Mitton, and Vorkink (2010) and in Zhang (2006), which are -67 and -36 basis points per month, respectively. While our robustness exercises sometimes yield smaller long-short portfolio returns, it is remarkable that we always obtain a negative estimate which is almost always statistically significant. In contrast, as discussed in Section 4.4, our implementation of the Zhang (2006) measure does not yield a statistically significant results, and we find that the results for the Boyer, Mitton, and Vorkink (2010) approach are sensitive to the window length used in the implementation. A more detailed comparison of realized skewness and these extant measures, and the implications of implementation choices, may prove worthwhile.

We have not addressed the measurement of expected skewness. We follow the approach used by Ang, Hodrick, Xing, and Zhang (2006) in the volatility literature, who sort the stocks based on volatility, and investigate subsequent returns. The underlying assumption is that the volatility in week $t$ is a good measure for the expected volatility in week $t+1$. However, Fu (2009) repeats the analysis of Ang, Hodrick, Xing, and Zhang (2006) using GARCH volatility as a measure of expected volatility, and finds that the results are sensitive to this. It is not straightforward to extend this type of analysis to skewness and kurtosis. Unlike volatility, skewness is not very persistent, and the modeling of conditional skewness is well-known to be challenging (Harvey and Siddique (1999)). Of course, using ex post realized skewness as a measure of expected skewness is not a solution either, because it is a noisy measure, and because the noise may simultaneously affect ex post returns and skewness. In summary, the relationship between realized skewness and expected skewness is of great interest, but it is a challenging problem.

We have also not addressed several other interesting extensions of our analysis. We have analyzed the cross-section of equity returns, but we have not investigated if realized higher moments are useful for time-series forecasting of future returns. A direct comparison of realized skewness and realized semivariance, proposed by Barndorff-Nielsen, Kinnebrock, and Shephard (2010) and

\footnotetext{
but we are not aware of results establishing a premium for kurtosis.

${ }^{7}$ In other related work, Kelly (2011) studies the relationship between tail estimates and returns. Cremers, Halling, and Weinbaum (2012) study the relationship between returns and aggregate jump risk.
} 
related to realized skewness, may also be of interest. Patton and Sheppard (2011) demonstrate that realized semivariance leads to improved forecasts of future volatility, which also suggests that realized skewness may be of interest for forecasting future volatility. Finally, it may prove interesting to repeat our exercise using jump estimates constructed from high-frequency data, as in Li (2012).

\section{Conclusion}

We document the cross-section of realized higher moments. We introduce model-free estimates of higher moments based on the methodology used by Hsieh (1991) and Andersen, Bollerslev, Diebold, and Ebens (2001) to estimate realized volatility. We use five-minute returns to obtain daily measures of higher moments, and subsequently aggregate this measure up to the weekly frequency. We find considerable time-variation in the cross-sectional distribution.

We then investigate the cross-sectional relationship between realized higher moments of individual stocks and future stock returns. We find a reliable and significant negative relationship between realized skewness and next week's stock returns in the cross-section. We find little evidence of a reliable relation between realized volatility and the cross-section of next week's stock returns. For realized kurtosis, overall the evidence indicates a positive relationship, but the result is not always robust to variations in the empirical setup. Fama-MacBeth regressions and double sorting confirm that realized skewness is not a proxy for firm characteristics such as size, book-to-market, realized volatility, market beta, lagged return, historical skewness, idiosyncratic volatility, coskewness, maximum return over the previous month or week, analysts coverage, illiquidity or number of intraday transactions.

We analyze the relationship between realized skewness and realized volatility in more detail. When double sorting on realized skewness and volatility, we find that stocks with negative skewness are compensated with high future returns for higher volatility. However, as skewness increases and becomes positive, the positive relation between volatility and returns turns into a negative relation. We conclude that investors may accept low returns and high volatility because they are attracted to high positive skewness. We perform a similar analysis for realized skewness and idiosyncratic volatility, and find that skewness may help explain the idiosyncratic volatility puzzle in Ang, Hodrick, Xing, and Zhang (2006), who document that stocks with high idiosyncratic volatility earn low returns. 


\section{References}

Ait-Sahalia, Y., and J. Yu, 2009, High Frequency Market Microstructure Noise Estimates and Liquidity Measures, Annals of Applied Statistics 3, 422-457.

Amihud, Y., 2002, Illiquidity and Stock Returns: Cross-Section and Time-Series Effects, Journal of Financial Markets 5, 31-56.

Andersen, T., and L. Benzoni, 2009, Realized Volatility, In: Andersen T. G., Davis R. A., Kreiss J.-P., Mikosch T. (Eds.), Handbook of Financial Time Series, 555-575, Springer, New York.

Andersen, T.G., and T. Bollerslev, 1998, Answering the Skeptics: Yes, Standard Volatility Models Do Provide Accurate Forecasts, International Economic Review 39, 885-905.

Andersen, T.G., T. Bollerslev, F.X. Diebold, and H. Ebens, 2001, The Distribution of Realized Stock Return Volatility, Journal of Financial Economics 61, 43-76.

Andersen, T.G., T. Bollerslev, F.X. Diebold, and P. Labys, 2000, Great Realizations, Risk, 105-108.

Andersen, T.G., T. Bollerslev, F.X. Diebold, and P. Labys, 2001, The Distribution of Realized Exchange Rate Volatility, Journal of the American Statistical Association 96, 42-55.

Andersen, T.G., T. Bollerslev, F.X. Diebold, and P. Labys, 2003, Modeling and Forecasting Realized Volatility, Econometrica, 71, 529-626.

Andersen, T.G., T. Bollerslev, and N. Meddahi, 2011, Realized Volatility Forecasting and Market Microstructure Noise, Journal of Econometrics 160, 220-234.

Andersen, T.G., D. Dobrev, and E. Schaumburg, 2010, Jump-Robust Volatility Estimation Using Nearest Neighbor Truncation, Journal of Econometrics 169, 75-93.

Ang, A., R.J. Hodrick, Y. Xing, and X. Zhang, 2006, The Cross-Section of Volatility and Expected Returns, Journal of Finance 61, 259-299.

Arbel, A., and P. Strebel, 1982, The Neglected and Small Firm Effects, Financial Review 17, 201-218.

Avramov, D., T. Chordia, and A. Goyal, 2006, Liquidity and Autocorrelations in Individual Stock Returns, Journal of Finance, 61, 2365-2394.

Bakshi, G., N. Kapadia, and D. Madan, 2003, Stock Return Characteristics, Skew Laws, and the Differential Pricing of Individual Equity Options, Review of Financial Studies 16, 101-143.

Bali, T., N. Cakici, and R. Whitelaw, 2009, Maxing Out: Stocks as Lotteries and the Cross-Section of Expected Returns, Journal of Financial Economics 99, 427-446. 
Barndorff-Nielsen, O. E., S. Kinnebrock, and N. Shephard, 2010, Measuring downside risk - realised semivariance, in Volatility and Time Series Econometrics: Essays in Honor of Robert F. Engle, ed. by T. Bollerslev, J. Russell, and M. Watson. Oxford University Press.

Barndorff-Nielsen, O.E., and N. Shephard, 2002, Econometric Analysis of Realised Volatility and its Use in Estimating Stochastic Volatility Models, Journal of the Royal Statistical Society 64, 253-280.

Barndorff-Nielsen, O.E., and N. Shephard, 2004, Power and Bipower Variation with Stochastic Volatility and Jumps, Journal of Financial Econometrics 2, 1-37.

Barberis, N., and M. Huang, 2008, Stocks as Lotteries: The Implications of Probability Weighting for Security Prices, American Economic Review 98, 2066-2100.

Bollerslev, T., D. Osterrieder, N. Sizova, and G. Tauchen, 2012, Risk and Return: Long-run Relations, Fractional Cointegration and Return Predictability, Journal of Financial Economics, forthcoming.

Bowley, A.L., 1920, Elements of Statistics, Scribner's, New York.

Boyer, B., T. Mitton, and K. Vorkink, 2010, Expected Idiosyncratic Skewness, Review of Financial Studies 23, 169-202.

Brunnermeier, M., C. Gollier , and J. Parker, 2007, Optimal Beliefs, Asset Prices and the Reference for Skewed Returns, American Economic Review 97, 159-165.

Carhart, M., 1997, On Persistence in Mutual Fund Performance, Journal of Finance 52, 57-82.

Chan, K.C., N. Chen, and D.A. Hsieh, 1985, An Exploratory Investigation of the Firm Size Effect, Journal of Financial Economics 14, 451-471.

Chakravarty, S., R. A. Wood, and R. A. Van Ness, 2004, Decimals and Liquidity: A Study Of The NYSE, Journal of Financial Research 27, 75-94.

Colacito, R., E. Ghysels, and J. Meng, 2012, Skewness in Expected Macro Fundamentals and the Predictability of Equity Returns: Evidence and Theory, University of North Carolina, Working Paper.

Conrad, J., R.F. Dittmar, and E. Ghysels, 2013, Ex Ante Skewness and Expected Stock Returns, Journal of Finance 68, 85-124.

Corsi, F., N. Fusari, and D. La Vecchia, 2013, Realizing smiles: Options Pricing with Realized Volatility, Journal of Financial Economics 107, 284-304.

Cremers, M., M. Halling, and D. Weinbaum, 2012, Aggregate Jump and Volatility Risk in the Cross-Section of Stock Returns, Working Paper, Notre Dame University. 
Cremers, M., A. Petajisto, and E. Zitzewitz, 2010, Should Benchmark Indices Have Alpha? Revisiting Performance Evaluation, Working Paper, Notre Dame University.

Dittmar, R.F., 2002, Nonlinear Pricing Kernels, Kurtosis Preference, and Evidence from the Cross Section of Equity, Journal of Finance 57, 369-403.

Duffie, D., J. Pan, and K. Singleton, 2000, Transform Analysis and Asset Pricing for Affine JumpDiffusions, Econometrica 68, 1343-1376.

Fama, E., and K. French, 1993, Common Risk Factors in the Returns on Stocks and Bonds, Journal of Financial Economics 33, 3-56.

Fama, E., and K. French, 2008, Dissecting Anomalies, Journal of Finance 63, 1653-1678.

Fama, E., and M. J. MacBeth, 1973, Risk, Return, and Equilibrium: Empirical Tests, Journal of Political Economy 81, 607-636.

Fleming, J., C. Kirby, and B. Ostdiek, 2003, The Economic Value of Volatility Timing Using "Realized" Volatility, Journal of Financial Economics 67, 473-509.

Frazzini, A., and L. Heje Pedersen, 2012, Betting Against Beta, Working Paper, NYU Stern.

Fu, F., 2009, Idiosyncratic Risk and the Cross-Section of Expected Stock Returns, Journal of Financial Economics 91, 24-37.

Golec, J., and M. Tamarkin, 1998, Bettors Love Skewness, not Risk, at the Horse Track, Journal of Political Economy 106, 205-225.

Gonçalves, S., and N. Meddahi, 2009, Bootstrapping Realized Volatility, Econometrica 77, 283-306.

Gutierrez Jr, R., and E. Kelley, 2008, The Long-Lasting Momentum in Weekly Returns, Journal of Finance 63, 415-447.

Harvey, C., and A. Siddique, 1999, Autoregressive Conditional Skewness, Journal of Financial and Quantitative Analysis 34, 465-487.

Harvey, C., and A. Siddique, 2000, Conditional Skewness in Asset Pricing Tests, Journal of Finance $55,1263-1295$.

Hsieh, D., 1991, Chaos and Nonlinear Dynamics: Application to Financial Markets, Journal of Finance, 46, 1839-1877.

Jacod, J., 2012, Statistics and High Frequency Data, In: M. Kessler, A. Lindner, and M. Sorensen (Eds.), Statistical Methods for Stochastic Differential Equations, Chapman \& Hall/CRC Monographs on Statistics \& Applied Probability, Volume 124. 
Jegadeesh, N., 1990, Evidence of Predictable Behavior of Security Returns, Journal of Finance 45, 881-898.

Keim, D.B., 1983, Size-Related Anomalies and Stock Return Seasonality, Journal of Financial Economics 12, 13-32.

Kelly, B., 2011, Tail Risk and Asset Prices, Chicago Booth Research Paper No. 11-17.

Kraus, A., and R. Litzenberger, 1976, Skewness Preference and the Valuation of Risk Assets, Journal of Finance 31, 1085-1100.

Lehmann, B.N., 1990, Fads, Martingales, and Market Efficiency, Quarterly Journal of Economics $105,1-28$.

Lesmond, D., J. Ogden, and C. Trzcinka, 1999, A New Estimate of Transaction Costs, Review of Financial Studies 12, 1113-1141.

Li, J., 2012, Robust Estimation and Inference for Jumps in Noisy High Frequency Data: A Localto-Continuity Theory for the Pre-Averaging Method, Working Paper, Duke University.

Merton, R., 1980, On Estimating the Expected Return on the Market: An Exploratory Investigation, Journal of Financial Economics 8, 323-361.

Mitton, T., and K. Vorkink, 2007, Equilibrium Underdiversification and the Preference for Skewness, Review of Financial Studies 20, 1255-1288.

Neuberger, A., 2012, Realized Skewness, Review of Financial Studies 25, 3423-3455.

Patton, A., and K. Sheppard, 2011, Good Volatility, Bad Volatility: Signed Jumps and the Persistence of Volatility, Working Paper, Duke University.

Paye, B., 2012, Déjà Vol': Predictive Regressions for Aggregate Stock Market Volatility Using Macroeconomic Variables, Journal of Financial Economics 106, 527-546.

Rehman, Z., and G. Vilkov, 2010, Risk-Neutral Skewness: Return Predictability and Its Sources, Working Paper, BlackRock and Goethe University.

Schwert, G.W., 1989, Why Does Stock Market Volatility Change Over Time?, Journal of Finance 44, 1115-1153.

Scott, R., and P. Horvath, 1980, On the Direction of Preference for Higher Order Moments, Journal of Finance 35, 915-919.

Xing, Y., X. Zhang, and R. Zhao, 2010, What Does the Individual Option Volatility Smirk Tell Us about Future Equity Returns?, Journal of Financial and Quantitative Analysis 45, 641-662. 
Zhang, L., P. Mykland, and Y. Ait-Sahalia, 2005, A Tale of Two Time Scales: Determining Integrated Volatility with Noisy High-Frequency Data, Journal of the American Statistical Association 100, 1394-1411.

Zhang, Y., 2006, Individual Skewness and the Cross-Section of Average Stock Returns, Working Paper. 


\section{Appendix A: Data}

- Following Fama and French (1993), size (in billions of dollars) is computed each June as the stock price times the number of outstanding shares. The market equity value is held constant for a year.

- Following Fama and French (1993), book-to-market is computed as the ratio of book common equity over market capitalization (size). Book common equity is defined using COMPUSTAT's book value of stockholders' equity plus balance-sheet deferred taxes and investment tax credit minus the book value of preferred stock. The ratio is then computed as the book common equity at the end of the fiscal year over size at the end of December.

- Historical skewness for stock $i$ on day $t$ is defined as

$$
H_{S k e w}, t=\frac{1}{N} \sum_{s=0}^{N}\left(\frac{r_{i, t-s}-\mu_{i}}{\sigma_{i}}\right)^{3},
$$

where $N$ is the number of trading days, $r_{i, t-s}$ is the daily log-return of stock $i$ on day $t-s$, $\mu_{i}$ is the mean for stock $i$ and $\sigma_{i}$ is the standard deviation of stock $i$. We estimate historical skewness using $1,6,12,24$, and 60 months of daily returns.

- Market beta is computed at the end of each month using a regression of daily returns over the past 12 months.

- Following Ang, Hodrick, Xing, and Zhang (2006), idiosyncratic volatility is defined as

$$
i d v o l_{i, t}=\sqrt{\operatorname{var}\left(\varepsilon_{i, t}\right)},
$$

where $\varepsilon_{i, t}$ is the error term of the three-factor Fama and French (1993) regression. The regression is estimated with daily returns over the previous 20 trading days.

- Following Harvey and Siddique (2000), coskewness is defined as

$$
\operatorname{CoSkew}_{i, t}=\frac{E\left[\varepsilon_{i, t} \varepsilon_{m, t}^{2}\right]}{\sqrt{E\left[\varepsilon_{i, t}^{2}\right]} E\left[\varepsilon_{m, t}^{2}\right]},
$$

where $\varepsilon_{i, t}$ is obtained from $\varepsilon_{i, t}=r_{i, t}-\alpha_{i}-\beta_{i} r_{m, t}$, where $r_{i, t}$ is the monthly return of stock $i$ on month $t, r_{m, t}$ is the market monthly return on month $t$. This regression is estimated at the end of each month using monthly returns for the past 24 months. ${ }^{8}$

- Maximum return is defined as the maximum daily return over the previous month or week.

\footnotetext{
${ }^{8}$ Harvey and Siddique (2000) use data for the past 60 months to estimate coskewness. This approach considerably reduces our sample of firms. We therefore estimate coskewness using only 24 months, which Harvey and Siddique (2000) also consider.
} 
- Following Avramov, Chordia, and Goyal (2006), Jegadeesh (1990), and Lehmann (1990), lagged return is defined as the weekly return over the previous week from Tuesday to Monday.

- Following Amihud (2002), stock illiquidity on day $t$ is measured as the average of the ratio of the absolute value of the return over the dollar value of the trading volume over the previous year

$$
\text { illiquidity }_{i, t}=\frac{1}{N} \sum_{s=0}^{N}\left(\frac{\left|r_{i, t-s}\right|}{\mid \text { volume }_{i, t-s} * \text { price }_{i, t-s} \mid}\right),
$$

where $N$ is the number of trading days, $r_{i, t-s}$ is the daily log-return of stock $i$ on day $t-s$, volume $_{i, t-s}$ is the daily volume of stock $i$ on day $t-s$, and price $_{i, t-s}$ is the price of stock $i$ on day $t-s$. We use 252 trading days to estimate illiquidity.

- The credit rating is retrieved from COMPUSTAT and is then assigned a numerical value as follows: $\mathrm{AAA}=1, \mathrm{AA}+=2, \mathrm{AA}=3, \mathrm{AA}-=4, \mathrm{~A}+=5, \mathrm{~A}=6, \mathrm{~A}-=7, \mathrm{BBB}+=8, \mathrm{BBB}=9, \mathrm{BBB}-$ $=10, \mathrm{BB}+=11, \mathrm{BB}=12, \mathrm{BB}-=13, \mathrm{~B}+=14, \mathrm{~B}=15, \mathrm{~B}-=16, \mathrm{CCC}+=17, \mathrm{CCC}=18, \mathrm{CCC}-19$, $\mathrm{CC}=20, \mathrm{C}=21$ and $\mathrm{D}=22$. When no rating is available, the default credit rating value is 8 .

\section{Appendix B: Expected Values of Realized Moment Limits}

To derive the expected value of the realized moment limits for the model in (12)-(13), we employ the fact that the log-price $p_{t}$ in equation (12) is an affine model, so there exists a closed-from solution for its moment generating function (MGF). In this appendix, we find an explicit representation of the forward MGF of $p_{t}$, which is then used to derive the expected value of the realized moment limits. From the MGF of $p_{t}$, see Duffie, Pan, and Singleton (2000), and using the law of iterated expectations, we have the forward MGF

$$
\begin{aligned}
\varphi_{t}(u, \tau) & \equiv E\left[\exp \left(u\left(p_{t+\tau}-p_{t}\right)\right) \mid \mathcal{F}_{0}\right] \\
& =E\left[E\left[\exp \left(u\left(p_{t+\tau}-p_{t}\right)\right) \mid \mathcal{F}_{t}\right] \mid \mathcal{F}_{0}\right] \\
& =E\left[\exp \left(\alpha(u, \tau)+\beta(u, \tau) V_{t}\right) \mid \mathcal{F}_{0}\right] \\
& =\exp (\alpha(u, \tau)) E\left[\exp \left(\beta(u, \tau) V_{t}\right) \mid \mathcal{F}_{0}\right] \\
& =\exp (\alpha(u, \tau)) \exp \left(-A(-\beta(u, \tau), t)-B(-\beta(u, \tau), t) V_{0}\right),
\end{aligned}
$$

where

$$
\begin{aligned}
A(\varsigma, t) & =\frac{\varsigma e^{-\kappa t}}{1+\varsigma \frac{\sigma^{2}}{2 \kappa}\left(1-e^{-\kappa t}\right)}, B(\varsigma, t)=\frac{2 \kappa \theta}{\sigma^{2}} \log \left(1+\varsigma \frac{\sigma^{2}}{2 \kappa}\left(1-e^{-\kappa t}\right)\right) \\
\alpha(u, t) & =\left(\mu-\lambda \bar{\mu}_{J}\right) u t-\frac{\kappa \theta}{\sigma^{2}}\left((\gamma+b) t+2 \log \left(1-\frac{\gamma+b}{2 \gamma}\left(1-e^{-\gamma t}\right)\right)\right)+\lambda t(\phi(u)-1)-\mu t, \\
\beta(u, t) & =-\frac{a\left(1-e^{-\gamma t}\right)}{2 \gamma-(\gamma+b)\left(1-e^{-\gamma t}\right)},
\end{aligned}
$$


with $a=u-u^{2}, b=\sigma \rho u-\kappa, \gamma=\sqrt{b^{2}+a \sigma^{2}}, \phi(u)=\exp \left(\mu_{J} u+\frac{1}{2} \sigma_{J}^{2} u^{2}\right)$, and $\tau=1 / N$.

We now need to find the expected value of the limits of the realized moments defined in (14),(15) and (16). We start by rewriting

$$
\begin{aligned}
\lim _{N \rightarrow \infty} E\left[\sum_{i=1}^{N}\left(p_{T \frac{i}{N}}-p_{T \frac{i-1}{N}}\right)^{j}\right] & =\lim _{N \rightarrow \infty} \sum_{i=1}^{N} E\left[\left(p_{T \frac{i}{N}}-p_{T \frac{i-1}{N}}\right)^{j}\right] \\
& =\left.\lim _{N \rightarrow \infty} \sum_{i=1}^{N} \frac{\partial^{j} \varphi_{T \frac{i-1}{N}}}{\partial u^{j}}(u, \tau)\right|_{u=0} .
\end{aligned}
$$

The Taylor series expansion of $\left.\frac{\partial^{j} \varphi_{t}}{\partial u^{j}}(u, \tau)\right|_{u=0}$ around $\tau=0$ yields

$$
\begin{aligned}
& \left.\frac{\partial^{2} \varphi_{t}}{\partial u^{2}}(u, \tau)\right|_{u=0}=\left(\theta+\lambda\left(\mu_{J}^{2}+\sigma_{J}^{2}\right)-e^{-\kappa t}\left(\theta-V_{0}\right)\right) \tau+O\left(\tau^{2}\right), \\
& \left.\frac{\partial^{3} \varphi_{t}}{\partial u^{3}}(u, \tau)\right|_{u=0}=\lambda\left(\mu_{J}^{3}+3 \mu_{J} \sigma_{J}^{2}\right) \tau+O\left(\tau^{2}\right), \\
& \left.\frac{\partial^{4} \varphi_{t}}{\partial u^{4}}(u, \tau)\right|_{u=0}=\lambda\left(\mu_{J}^{4}+6 \mu_{J}^{2} \sigma_{J}^{2}+3 \sigma_{J}^{4}\right) \tau+O\left(\tau^{2}\right),
\end{aligned}
$$

where $O\left(\tau^{2}\right)$ denotes all terms of order 2 and above. As $N$ tends to infinity, $\tau$ converges to zero, so that the only remaining terms in equations (27), (28), and (29) are those of order 1 . The limit of the sum of these terms coincides with the definition of the Riemann-Stieltjes integral, so that integrating these terms with respect to $t$ over the sampling interval $[0, T]$ gives (14), (15), and (16) .

\section{Appendix C: Monte Carlo Evidence}

In practice, microstructure noise is present in high frequency prices. To simulate market microstructure noise, we define the observed $\log$ price $p_{t}^{*}$ as

$$
p_{t}^{*}=p_{t}+u_{t}
$$

where $u_{t}$ is i.i.d. Gaussian noise with mean zero and variance $\sigma_{u}^{2}$. Hence, the observed log price $p_{t}^{*}$ is a noisy observation of the non-observable true price $p_{t}$.

Several studies use Monte Carlo simulations to investigate the properties of realized variance estimators when allowing for market microstructure noise, see for instance Andersen, Bollerslev, and Meddahi (2011), Gonçalves and Meddahi (2009), and Ait-Sahalia and Yu (2009). Based on their work, we conduct the following Monte Carlo study.

We simulate 100,000 paths of the log price process $p_{t}$ using the Euler scheme at a time interval $\tau=1$ second. The parameters for the continuous part of the process are set to $\mu=0.05, \kappa=5$, $\theta=0.04, \sigma=0.5, V_{0}=0.09$, and $\rho=-0.5$. The microstructure noise, $u_{t}$, is modeled with a normal distribution of mean zero and standard deviation of $0.05 \%$. These parameter values are similar to 
those employed by Ait-Sahalia and Yu (2009). The parameters for the jump component are set at $\lambda=100, \mu_{J}=0.01$, and $\sigma_{J}=0.05$.

To assess the impact of the microstructure noise at different sampling frequencies, we use signature plots as proposed in Andersen, Bollerslev, Diebold, and Labys (2000). The signature plots provide the sample mean of a daily realized moment based on returns sampled at different intraday frequencies. We take as an observation period $T=1$ day, that is $T=1 / 252$, and we assume a day has 6.5 trading hours.

Panel A of Figure A.1 shows the signature plots of $R M(j)$ as defined in (9), (10), and (11). This figure includes $99 \%$ confidence bands around the Monte Carlo estimates. For the second moments in the first row of panels the confidence intervals are very tight around the Monte Carlo estimate making them barely noticeable in the plot. For the third and fourth moments (the second and third row of panels), the $99 \%$ confidence intervals contain the Monte Carlo estimate as well as the theoretical limit.

The signature plot for the second moment $R M(2)$ depicts the well-known effect that microstructure noise has on realized volatility: as the sampling frequency increases (moving from right to left in the figure), the variance of the noise dominates that of the price process; but for lower frequencies, this effect attenuates. In contrast, the microstructure noise does not affect the signature plots of $R M(3)$ and $R M(4)$ in the same way. There is a small and insignificant bias in $R M(3)$ and $R M(4)$ relative to $I M(3)$ and $I M(4)$ but the bias does not increase with the intraday frequency.

Chakravarty, Wood, and Van Ness (2004) document that bid-ask spreads declined significantly following the decimalization of NYSE-listed companies in 2001. This indicates that predecimalization prices exhibit an additional bid-ask spread generated by fractional minimum increments. To gauge the effect of this discontinuity on the realized moment measures, we conduct a Monte Carlo study similar to the one above, with the exception that observed prices are now measured in sixteenths of a dollar. To isolate the effect of fractional minimum increments, we assume here that observed prices are not affected by microstructure noise.

Panel B of Figure A.1 shows the signature plots for the realized moments. The plots reveal that realized volatility is the only moment affected by fractional changes in observed prices. As the frequency increases, the discontinuity of observed prices creates noise that is picked up by the volatility measure. However, the noise does not affect the third and fourth moments as shown by the $99 \%$ confidence intervals, which contain the Monte Carlo estimate as well as the theoretical limit. 
Figure 1

Histogram and Percentiles of Realized Moments

We display histograms and various percentiles of realized moments for the cross-section of stocks over the period January 1993 to September 2008. Figures for realized volatility, realized skewness, and realized kurtosis are reported in Panel A, Panel B, and Panel C respectively. The sample contains 2,052,752 firmweek observations.

Panel A: Realized Volatility

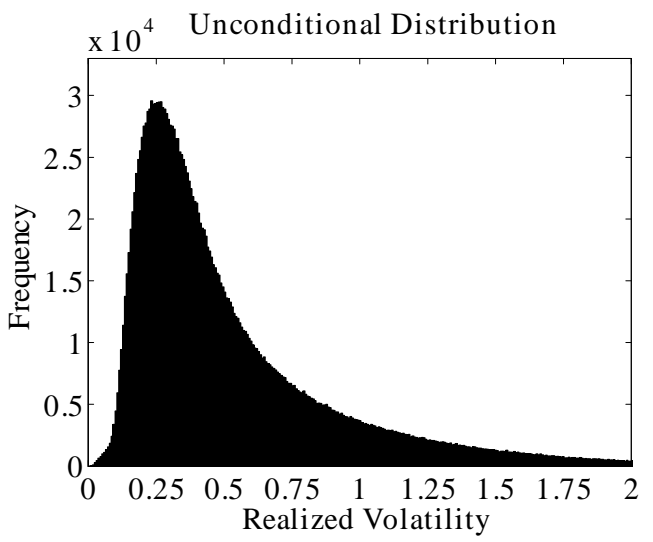

Cross-Sectional Percentiles

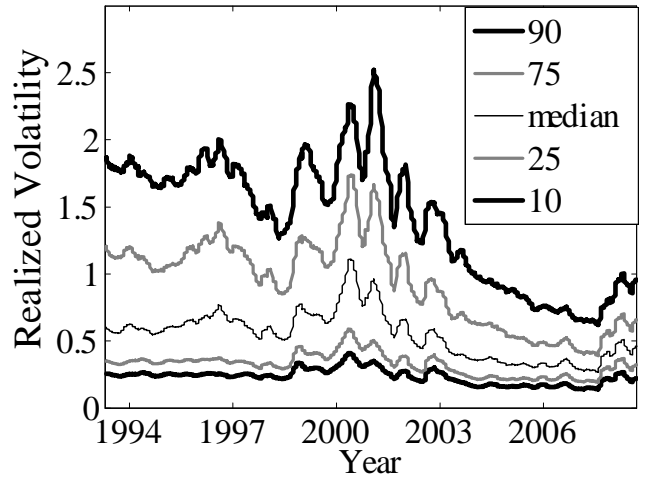

Panel B: Realized Skewness
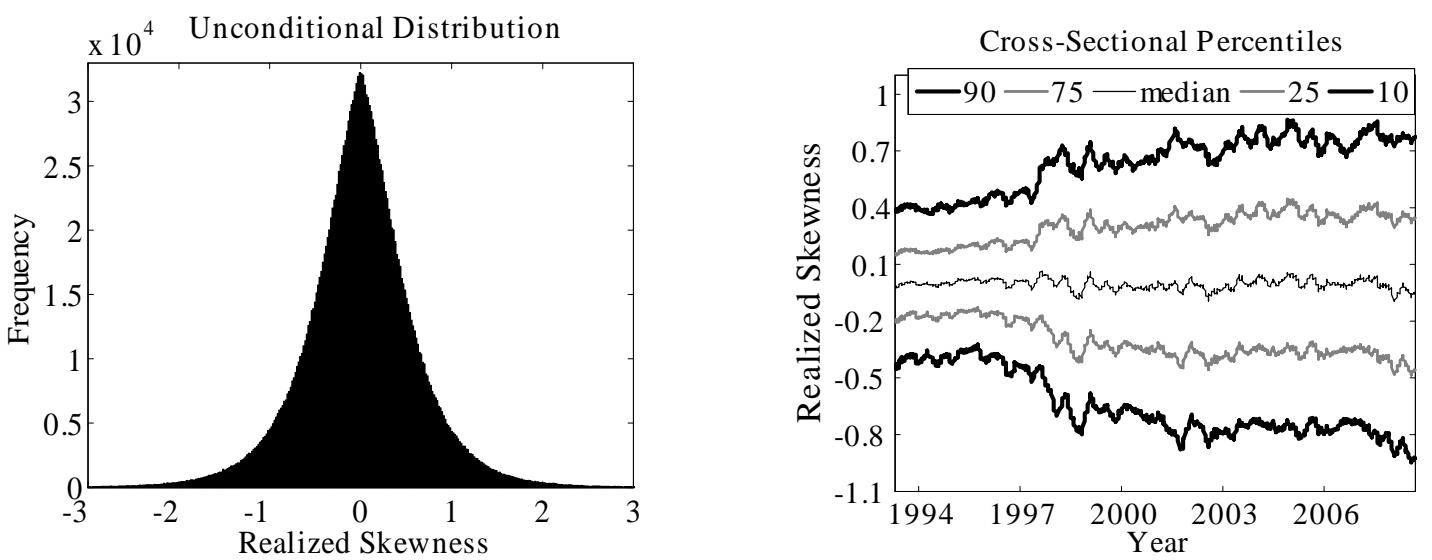

Panel C: Realized Kurtosis
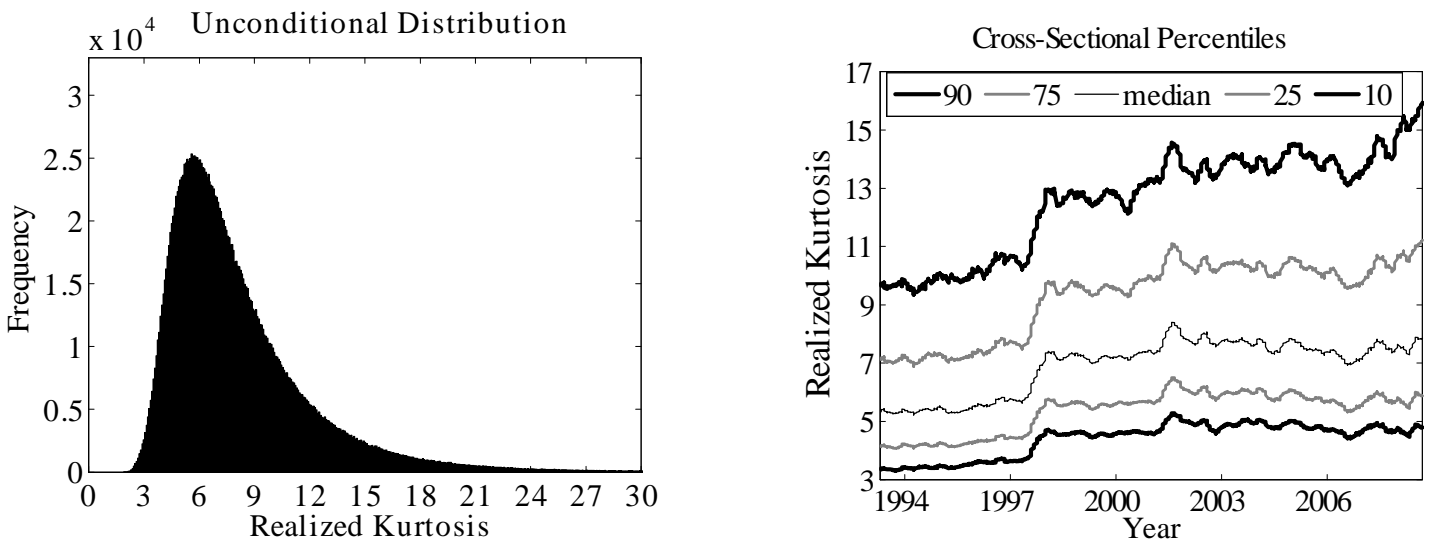
Figure 2

Realized Moments by Firm Characteristic

We display terciles of realized moments by size, book-to-market, and market beta. Panel A displays results for three size groups, Panel B for three book-to-market groups, and Panel C for three market beta groups. The sample period is January 1993 to September 2008.

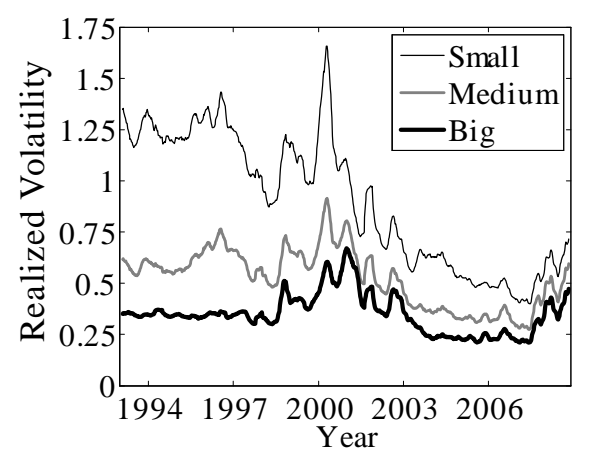

Panel A: by Size

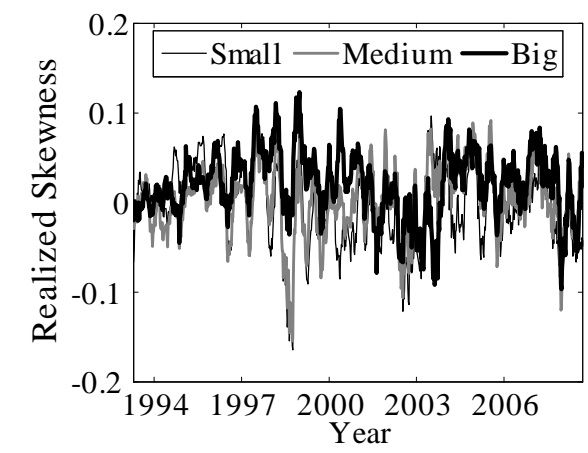

Panel B: by Book to Market

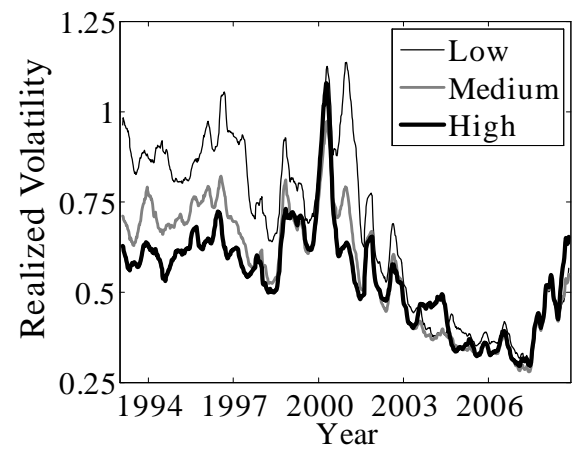

Panel C: by Market Beta

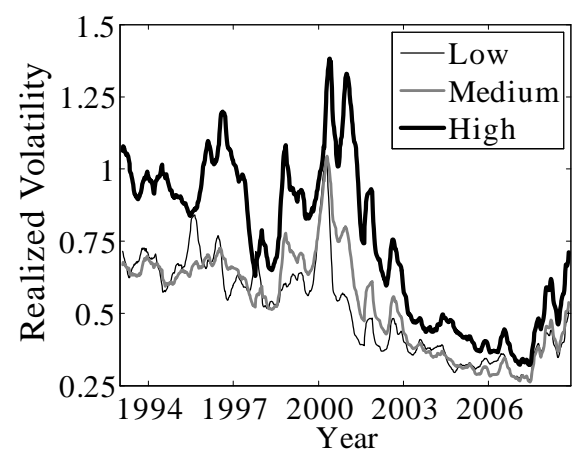

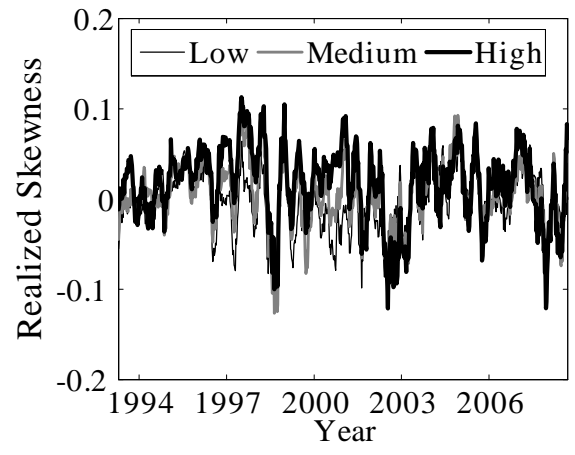
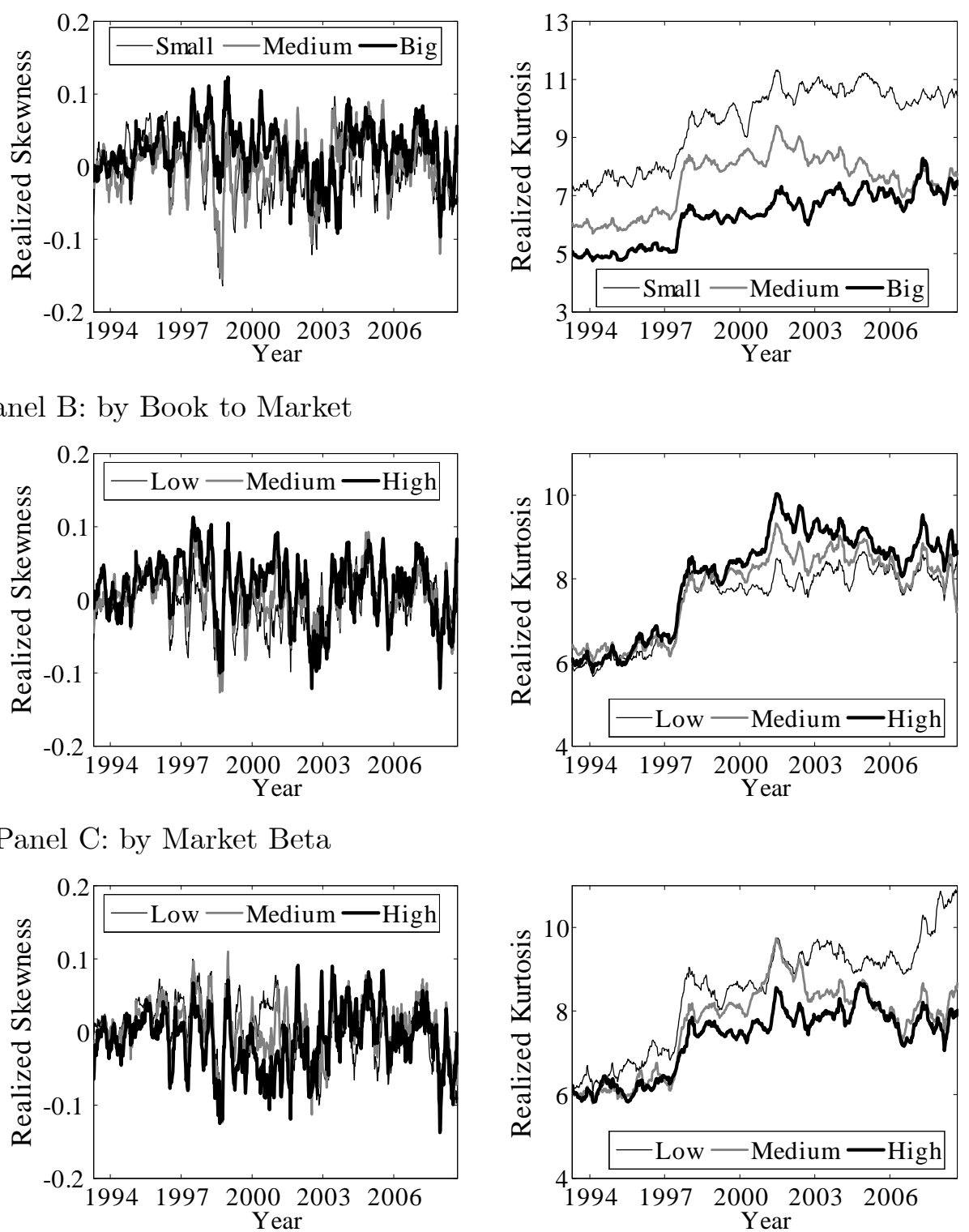
Figure 3

Interaction between Realized Volatility, Realized Skewness, and Stock Returns

Each week, stocks are first ranked by realized skewness into five quintiles and then, within each quintile, stocks are sorted once again into five quintiles by realized volatility (Panel A) and idiosyncratic volatility (Panel B). We report value- and equal-weighted returns (in bps) for different levels of volatility and realized skewness. Each line represents different quintiles of realized skewness. The average realized skewness in each quintile is reported in parentheses.

Panel A: Interaction between Realized Volatility,

Realized Skewness, and Stock Returns

Value-Weighted

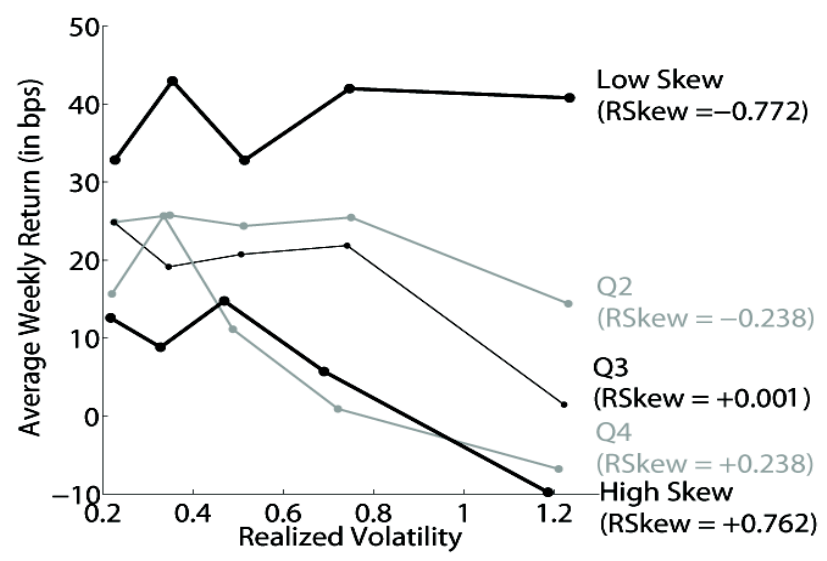

Equal-Weighted

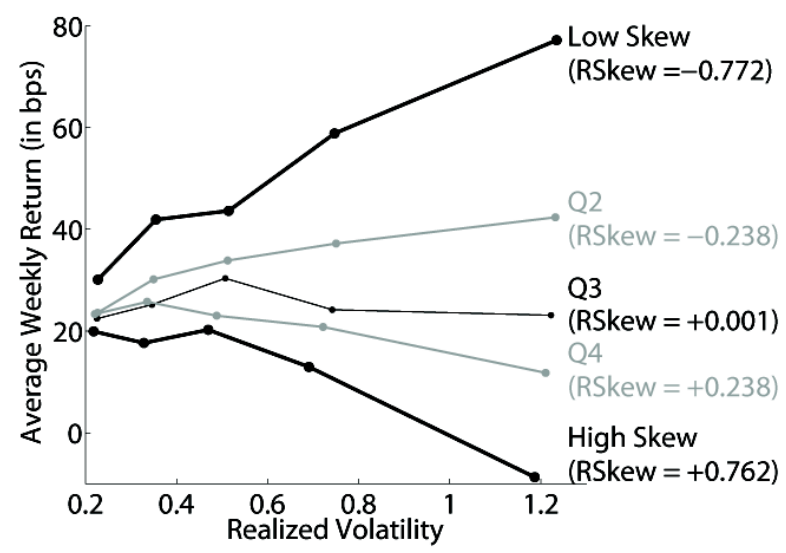

Panel B: Interaction between Idiosyncratic Volatility, Realized Skewness, and Stock Returns

Value-Weighted

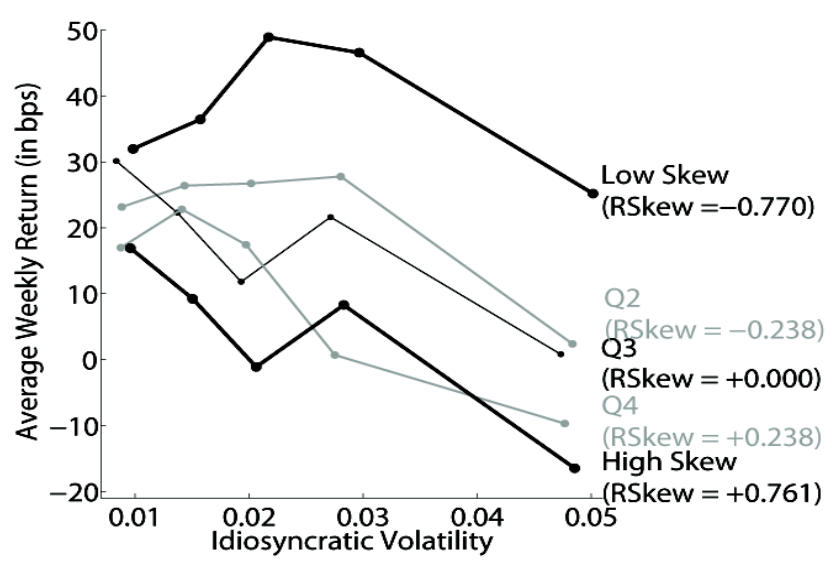

Equal-Weighted

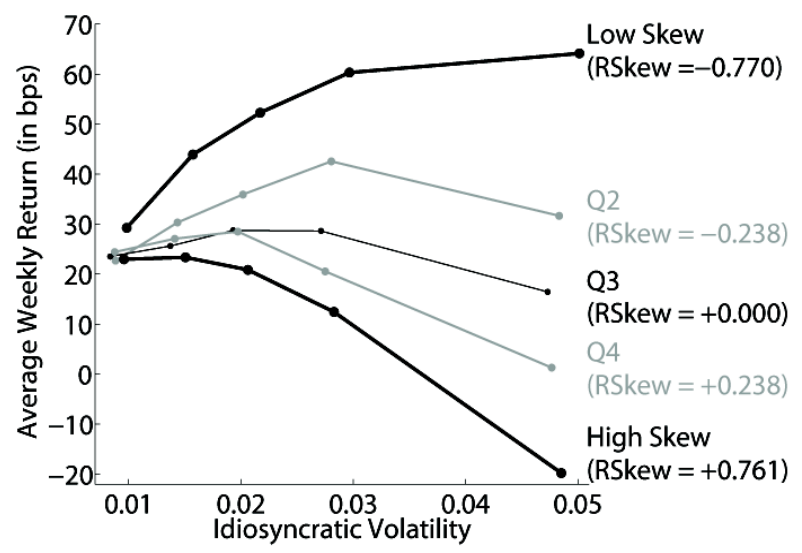


Figure A.1

Signature Plots for Realized Moments

We show signature plots for the three daily realized moments, $R M(2), R M(3)$, and $R M(4)$ computed using equations (9), (10), and (11). The intraday sampling frequency on the horizontal axis is in seconds. The dotted lines represent the theoretical limit of realized moments as given by equations (14), (15), and (16). Monte Carlo estimates are plotted in continuous dark lines. Confidence intervals at $99 \%$ are shown in grey lines. In Panel A, observed prices have a microstructure noise component, which is simulated from a mean-zero normal distribution with a standard deviation of $0.05 \%$. In Panel B, prices are only observed in sixteenths of a dollar.

Panel A:

Market Microstructure Noise
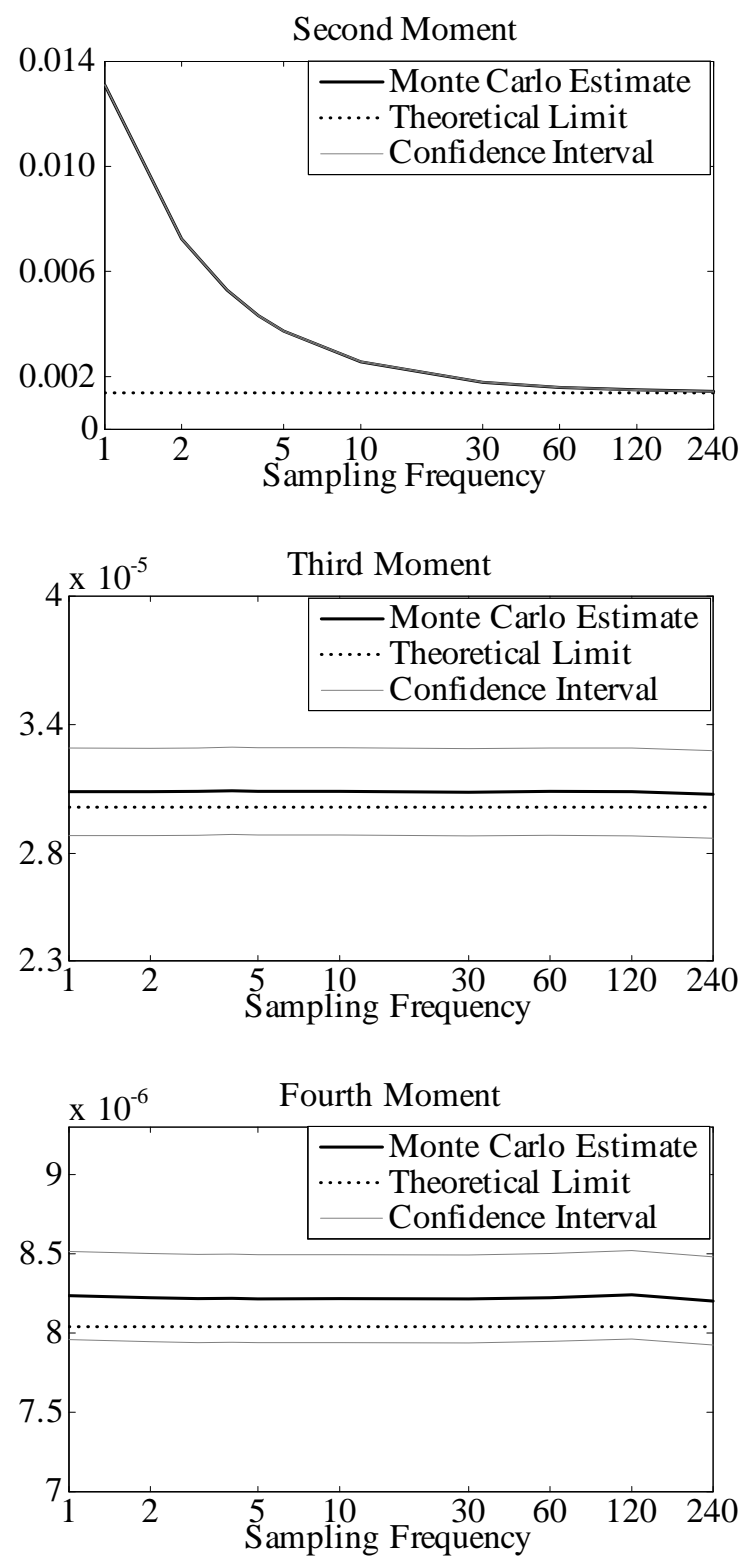

Panel B:

Discrete Price Changes
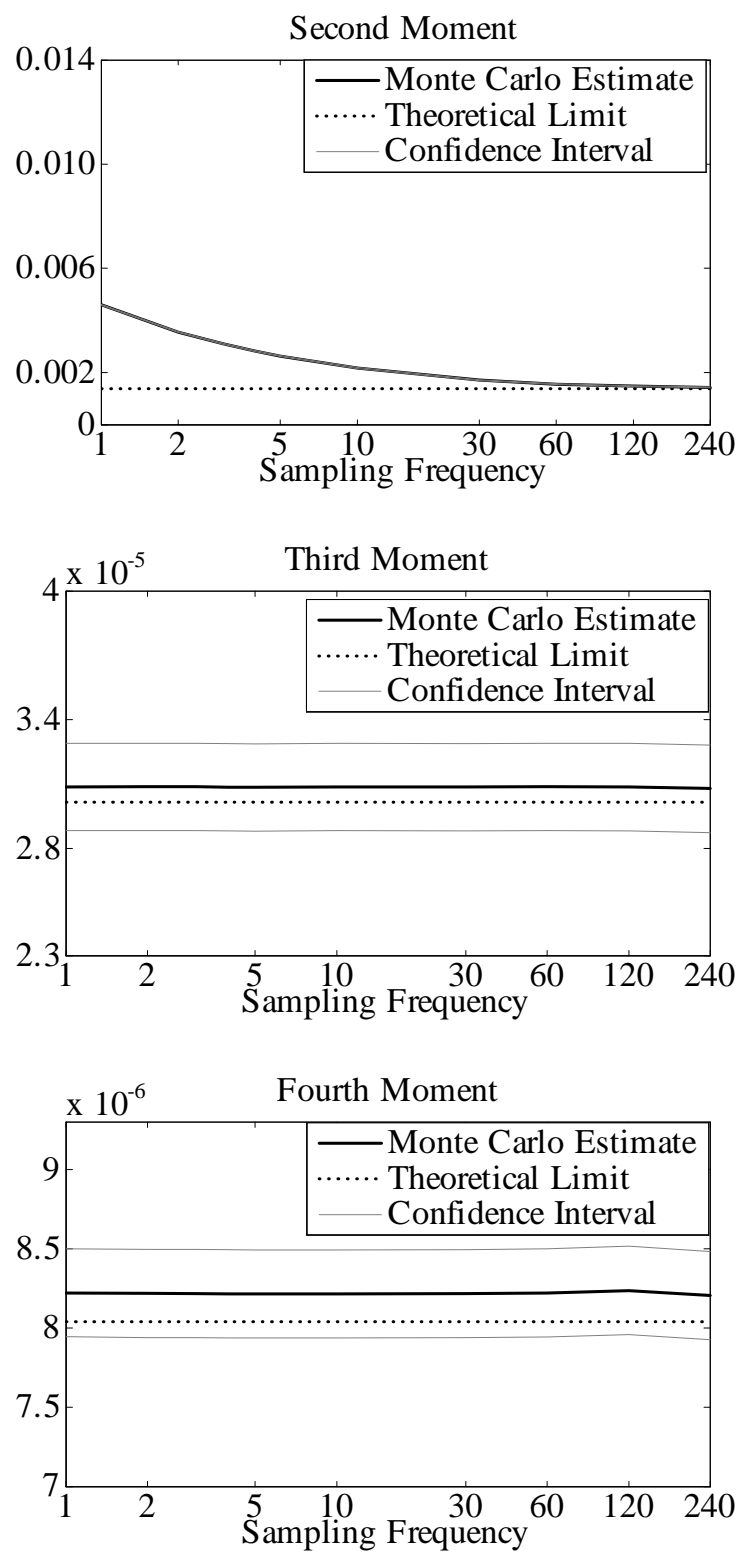
Table 1

Characteristics of Portfolios Sorted by Realized Moments

Each week, stocks are ranked by their realized moment and sorted into deciles. The equal-weighted characteristics of those deciles are computed over the same week. This procedure is repeated for every week from January 1993 through September 2008. Panel A displays the average results for realized volatility, Panel B for realized skewness, and Panel C for realized kurtosis. Average characteristics of the portfolios are reported for the realized moment, Size (market capitalization in \$billions), BE/ME (book-to-market equity ratio), Realized volatility (weekly realized volatility computed with high-frequency data), Historical Skewness (one month historical skewness from daily returns), Market Beta, Lagged Return, Idiosyncratic Volatility (computed as in Ang, Hodrick, Xing, and Zhang (2006)), Coskewness (computed as in Harvey and Siddique (2000)), Maximum Return (of the previous month), Illiquidity (annual average of the absolute return over daily dollar trading volume times $10^{6}$, as in Amihud (2002)), Number of Analysts (from I/B/E/S), Credit Rating $(1=\mathrm{AAA}, 8=\mathrm{BBB}+, 17=\mathrm{CCC}+, 22=\mathrm{D}$ ), Price (stock price), Intraday Transactions (intraday transactions per day) and Number of Stocks.

Panel A: Characteristics of Portfolios Sorted by Realized Volatility

\begin{tabular}{rcccccccccc}
\hline Deciles & 1 & 2 & 3 & 4 & 5 & 6 & 7 & 8 & 9 & 10 \\
\hline & & & & & & & & & & \\
Realized Volatility & 0.188 & 0.254 & 0.308 & 0.369 & 0.447 & 0.543 & 0.660 & 0.803 & 1.001 & 1.450 \\
Realized Skewness & 0.024 & 0.020 & 0.012 & 0.004 & 0.000 & -0.004 & -0.009 & -0.014 & -0.024 & -0.026 \\
Realized Kurtosis & 7.0 & 6.9 & 7.0 & 7.2 & 7.5 & 7.8 & 8.1 & 8.4 & 8.8 & 9.4 \\
Size & 13.84 & 12.14 & 9.04 & 6.19 & 4.26 & 2.89 & 1.91 & 1.21 & 0.79 & 0.46 \\
BE/ME & 0.654 & 0.573 & 0.509 & 0.507 & 0.488 & 0.459 & 0.428 & 0.421 & 0.417 & 0.440 \\
Market Beta & 0.72 & 0.82 & 0.89 & 0.97 & 1.07 & 1.18 & 1.28 & 1.36 & 1.36 & 1.32 \\
Historical Skewness & 0.109 & 0.102 & 0.109 & 0.126 & 0.144 & 0.166 & 0.191 & 0.212 & 0.241 & 0.311 \\
Lagged Return & 0.003 & 0.004 & 0.004 & 0.005 & 0.005 & 0.006 & 0.007 & 0.008 & 0.010 & 0.028 \\
Coskewness & 0.003 & -0.007 & -0.018 & -0.028 & -0.032 & -0.035 & -0.041 & -0.045 & -0.049 & -0.050 \\
Idiosyncratic Volatility & 0.011 & 0.013 & 0.015 & 0.017 & 0.020 & 0.023 & 0.027 & 0.031 & 0.036 & 0.048 \\
Maximum Return & 0.032 & 0.036 & 0.041 & 0.047 & 0.055 & 0.064 & 0.074 & 0.085 & 0.099 & 0.137 \\
Number of Analysts & 0.005 & 0.005 & 0.006 & 0.009 & 0.013 & 0.020 & 0.035 & 0.080 & 0.126 & 0.562 \\
Credit Rating & 7.0 & 10.6 & 10.2 & 9.5 & 8.8 & 7.9 & 6.9 & 5.8 & 4.7 & 3.2 \\
Price & 62.2 & 53.6 & 38.9 & 33.5 & 29.6 & 27.7 & 24.7 & 21.4 & 17.8 & 15.0 \\
Intraday Transactions & 1,216 & 1,499 & 1,576 & 1,568 & 1,628 & 1,617 & 1,558 & 1,438 & 1,268 & 1,189 \\
Number of Stocks & 256 & 257 & 257 & 257 & 257 & 257 & 257 & 257 & 257 & 257 \\
\hline
\end{tabular}


Table 1 (Continued)

Panel B: Characteristics of Portfolios Sorted by Realized Skewness

\begin{tabular}{rcccccccccc}
\hline Deciles & 1 & 2 & 3 & 4 & 5 & 6 & 7 & 8 & 9 & 10 \\
\hline & & & & & & & & & & \\
Realized Skewness & -1.04 & -0.50 & -0.31 & -0.17 & -0.05 & 0.05 & 0.17 & 0.31 & 0.50 & 1.02 \\
Realized Volatility & 0.618 & 0.613 & 0.614 & 0.614 & 0.610 & 0.606 & 0.600 & 0.590 & 0.577 & 0.579 \\
Realized Kurtosis & 11.4 & 7.9 & 7.0 & 6.6 & 6.4 & 6.4 & 6.6 & 7.0 & 7.8 & 11.1 \\
Size & 2.96 & 4.41 & 5.22 & 5.75 & 6.22 & 6.22 & 6.09 & 5.69 & 4.91 & 3.49 \\
BE/ME & 0.476 & 0.471 & 0.480 & 0.483 & 0.486 & 0.488 & 0.500 & 0.495 & 0.488 & 0.490 \\
Market Beta & 1.05 & 1.14 & 1.12 & 1.11 & 1.09 & 1.10 & 1.11 & 1.11 & 1.10 & 1.02 \\
Historical Skewness & 0.140 & 0.160 & 0.163 & 0.167 & 0.162 & 0.167 & 0.171 & 0.173 & 0.184 & 0.209 \\
Lagged Return & -0.041 & -0.025 & -0.014 & -0.006 & 0.003 & 0.011 & 0.020 & 0.030 & 0.042 & 0.061 \\
Coskewness & -0.038 & -0.031 & -0.028 & -0.029 & -0.027 & -0.026 & -0.025 & -0.024 & -0.025 & -0.027 \\
Idiosyncratic Volatility & 0.026 & 0.025 & 0.024 & 0.024 & 0.023 & 0.023 & 0.023 & 0.024 & 0.024 & 0.025 \\
Maximum Return & 0.067 & 0.067 & 0.066 & 0.065 & 0.065 & 0.065 & 0.066 & 0.068 & 0.069 & 0.072 \\
Illiquidity & 0.116 & 0.071 & 0.082 & 0.066 & 0.076 & 0.059 & 0.058 & 0.067 & 0.102 & 0.158 \\
Number of Analysts & 6.5 & 7.6 & 7.9 & 8.1 & 8.1 & 8.1 & 8.2 & 8.2 & 8.0 & 6.9 \\
Credit Rating & 8.4 & 8.3 & 8.3 & 8.3 & 8.3 & 8.3 & 8.3 & 8.3 & 8.3 & 8.4 \\
Price & 29.8 & 32.6 & 33.2 & 32.2 & 31.5 & 31.4 & 33.0 & 33.7 & 33.9 & 33.1 \\
Intraday Transactions & 998 & 1,324 & 1,516 & 1,613 & 1,676 & 1,683 & 1,633 & 1,595 & 1,426 & 1,095 \\
Number of Stocks & 256 & 257 & 257 & 257 & 257 & 257 & 257 & 257 & 257 & 257 \\
\hline
\end{tabular}

Panel C: Characteristics of Portfolios Sorted by Realized Kurtosis

\begin{tabular}{rcccccccccc}
\hline Deciles & 1 & 2 & 3 & 4 & 5 & 6 & 7 & 8 & 9 & 10 \\
\hline & & & & & & & & & & \\
Realized Kurtosis & 3.9 & 4.7 & 5.3 & 5.9 & 6.5 & 7.2 & 8.0 & 9.2 & 10.9 & 16.6 \\
Realized Volatility & 0.485 & 0.537 & 0.570 & 0.589 & 0.603 & 0.614 & 0.623 & 0.638 & 0.654 & 0.711 \\
Realized Skewness & 0.005 & 0.007 & 0.006 & 0.006 & 0.007 & 0.003 & 0.000 & -0.006 & -0.012 & -0.034 \\
Size & 15.59 & 8.80 & 6.22 & 4.89 & 3.88 & 3.27 & 2.80 & 2.38 & 1.98 & 1.36 \\
BE/ME & 0.481 & 0.492 & 0.476 & 0.502 & 0.477 & 0.478 & 0.476 & 0.480 & 0.480 & 0.514 \\
Hskew & 0.129 & 0.149 & 0.156 & 0.165 & 0.170 & 0.166 & 0.180 & 0.177 & 0.186 & 0.220 \\
Beta & 1.09 & 1.15 & 1.16 & 1.15 & 1.14 & 1.13 & 1.12 & 1.08 & 1.03 & 0.90 \\
Lagged Return & 0.004 & 0.006 & 0.007 & 0.007 & 0.008 & 0.008 & 0.008 & 0.008 & 0.009 & 0.015 \\
Coskewness & -0.012 & -0.017 & -0.020 & -0.023 & -0.027 & -0.030 & -0.031 & -0.036 & -0.040 & -0.046 \\
Idiosyncratic Volatility & 0.019 & 0.022 & 0.023 & 0.024 & 0.024 & 0.025 & 0.025 & 0.026 & 0.026 & 0.027 \\
Maximum Return & 0.053 & 0.061 & 0.065 & 0.067 & 0.068 & 0.069 & 0.070 & 0.070 & 0.071 & 0.076 \\
Number of Analysts & 0.014 & 0.029 & 0.035 & 0.046 & 0.061 & 0.070 & 0.074 & 0.109 & 0.112 & 0.306 \\
Credit Rating & 7.8 & 10.1 & 9.1 & 8.4 & 7.8 & 7.4 & 6.9 & 6.4 & 5.8 & 4.4 \\
Price & 36.4 & 37.9 & 36.2 & 34.0 & 33.6 & 32.4 & 30.2 & 29.5 & 28.6 & 25.6 \\
Intraday Transactions & 3,250 & 2,195 & 1,795 & 1,553 & 1,349 & 1,217 & 1,067 & 917 & 736 & 483 \\
Number of Stocks & 256 & 257 & 257 & 257 & 257 & 257 & 257 & 257 & 257 & 257 \\
\hline
\end{tabular}


Table 2

Realized Moments and the Cross-Section of Stock Returns

We report value- and equal-weighted weekly returns (in bps) of decile portfolios formed from realized moments, the corresponding t-statistics (in parentheses), and the return difference between portfolio 10 (highest realized moment) and portfolio 1 (lowest realized moment) over the period January 1993 to September 2008. Panel A displays the results for realized volatility, Panel B for realized skewness, and Panel C for realized kurtosis. Each panel reports the value-weighted portfolios and the equal-weighted portfolios. Raw returns (in bps) are obtained from decile portfolios sorted solely from ranking stocks based on the realized moment measure. Alpha is the intercept from time-series regressions of the returns of the portfolio using the Carhart four factor model.

Panel A: Realized Volatility and the Cross-Section of Stock Returns

\begin{tabular}{|c|c|c|c|c|c|c|c|c|c|c|c|}
\hline & Low & 2 & 3 & 4 & 5 & 6 & 7 & 8 & 9 & High & High-Low \\
\hline & \multicolumn{11}{|c|}{ Value weighted } \\
\hline \multirow[t]{2}{*}{ Raw Returns } & 19.98 & 21.66 & 26.28 & 20.59 & 18.41 & 18.10 & 19.51 & 14.09 & 17.01 & 8.07 & -11.92 \\
\hline & $(3.24)$ & $(3.06)$ & $(3.27)$ & $(2.19)$ & $(1.69)$ & $(1.39)$ & $(1.32)$ & $(0.81)$ & $(0.93)$ & $(0.41)$ & $(-0.65)$ \\
\hline \multirow[t]{3}{*}{ Alpha, C4 } & 7.04 & 7.39 & 11.54 & 7.75 & 6.96 & 8.52 & 10.00 & 6.42 & 11.68 & 5.45 & -3.25 \\
\hline & $(2.22)$ & $(2.53)$ & $(3.94)$ & $(2.23)$ & $(1.64)$ & $(1.52)$ & $(1.63)$ & $(0.90)$ & $(1.39)$ & $(0.53)$ & $(-0.29)$ \\
\hline & \multicolumn{11}{|c|}{ Equal weighted } \\
\hline \multirow[t]{2}{*}{ Raw Returns } & 21.96 & 24.10 & 25.82 & 30.19 & 28.56 & 31.92 & 29.15 & 32.04 & 34.04 & 27.04 & 5.08 \\
\hline & $(3.93)$ & $(3.62)$ & $(3.55)$ & $(3.75)$ & $(3.13)$ & $(2.97)$ & $(2.35)$ & $(2.29)$ & $(2.16)$ & $(1.55)$ & $(0.33)$ \\
\hline \multirow[t]{2}{*}{ Alpha, C4 } & 7.56 & 7.77 & 8.78 & 12.44 & 10.19 & 14.92 & 12.24 & 17.61 & 20.41 & 13.71 & 4.48 \\
\hline & (3.12) & (3.34) & $(3.72)$ & $(5.11)$ & $(4.08)$ & $(4.95)$ & $(3.46)$ & $(4.21)$ & $(3.76)$ & $(1.85)$ & $(0.54)$ \\
\hline
\end{tabular}

Panel B: Realized Skewness and the Cross-Section of Stock Returns

\begin{tabular}{|c|c|c|c|c|c|c|c|c|c|c|c|}
\hline & Low & 2 & 3 & 4 & 5 & 6 & 7 & 8 & 9 & High & High-Low \\
\hline & \multicolumn{11}{|c|}{ Value weighted } \\
\hline \multirow[t]{2}{*}{ Raw Returns } & 40.49 & 33.84 & 27.24 & 19.93 & 26.64 & 15.61 & 20.58 & 9.00 & 5.25 & 16.69 & -23.80 \\
\hline & $(4.12)$ & $(3.49)$ & $(2.77)$ & $(1.96)$ & $(2.83)$ & $(1.76)$ & $(2.29)$ & $(1.00)$ & $(0.61)$ & $(1.98)$ & $(-3.65)$ \\
\hline \multirow[t]{3}{*}{ Alpha, C4 } & 27.58 & 22.72 & 16.85 & 9.92 & 20.20 & 7.42 & 10.73 & 0.24 & -7.34 & 4.85 & -24.39 \\
\hline & $(5.56)$ & $(5.58)$ & $(4.25)$ & $(2.39)$ & $(5.56)$ & $(2.45)$ & $(3.06)$ & $(0.07)$ & $(-2.26)$ & $(1.22)$ & $(-3.74)$ \\
\hline & \multicolumn{11}{|c|}{ Equal weighted } \\
\hline \multirow[t]{2}{*}{ Raw Returns } & 54.99 & 45.73 & 36.08 & 30.78 & 29.43 & 21.13 & 23.78 & 18.22 & 13.29 & 11.54 & -43.44 \\
\hline & $(5.06)$ & $(4.12)$ & $(3.31)$ & $(2.91)$ & $(2.87)$ & $(2.11)$ & $(2.41)$ & $(1.87)$ & $(1.41)$ & $(1.29)$ & $(-8.91)$ \\
\hline \multirow[t]{2}{*}{ Alpha, C4 } & 37.60 & 29.04 & 20.58 & 15.61 & 14.22 & 6.16 & 8.44 & 2.23 & -2.86 & -5.24 & -44.49 \\
\hline & $(9.17)$ & $(7.92)$ & $(6.30)$ & (5.13) & (5.19) & $(2.50)$ & $(3.32)$ & $(0.86)$ & $(-1.10)$ & $(-1.79)$ & $(-9.66)$ \\
\hline
\end{tabular}

Panel C: Realized Kurtosis and the Cross-Section of Stock Returns

\begin{tabular}{|c|c|c|c|c|c|c|c|c|c|c|c|}
\hline & Low & 2 & 3 & 4 & 5 & 6 & 7 & 8 & 9 & High & High-Low \\
\hline & \multicolumn{11}{|c|}{ Value weighted } \\
\hline \multirow[t]{2}{*}{ Raw Returns } & 17.17 & 20.83 & 18.30 & 27.24 & 17.55 & 15.04 & 21.81 & 26.27 & 18.91 & 30.74 & 13.57 \\
\hline & $(1.80)$ & $(2.32)$ & $(2.06)$ & $(3.06)$ & $(1.93)$ & $(1.61)$ & $(2.47)$ & $(2.81)$ & $(2.16)$ & $(3.58)$ & $(2.12)$ \\
\hline \multirow[t]{3}{*}{ Alpha, C4 } & 9.01 & 10.87 & 6.79 & 17.13 & 6.41 & 3.33 & 8.94 & 12.83 & 5.91 & 17.52 & 6.85 \\
\hline & $(2.83)$ & $(3.96)$ & $(2.07)$ & $(5.24)$ & $(1.78)$ & $(0.88)$ & $(2.54)$ & $(2.97)$ & $(1.39)$ & $(3.87)$ & $(1.16)$ \\
\hline & \multicolumn{11}{|c|}{ Equal weighted } \\
\hline \multirow[t]{2}{*}{ Raw Returns } & 22.68 & 25.66 & 25.81 & 25.25 & 27.30 & 27.00 & 27.86 & 30.47 & 34.39 & 38.45 & 15.77 \\
\hline & $(2.28)$ & $(2.52)$ & $(2.48)$ & $(2.37)$ & $(2.58)$ & $(2.59)$ & $(2.70)$ & $(2.96)$ & $(3.45)$ & $(4.21)$ & $(2.98)$ \\
\hline \multirow[t]{2}{*}{ Alpha, C4 } & 12.29 & 11.51 & 10.39 & 8.89 & 10.02 & 10.02 & 10.37 & 13.13 & 17.17 & 21.91 & 7.97 \\
\hline & $(4.44)$ & $(4.33)$ & $(3.71)$ & $(3.04)$ & $(3.37)$ & $(3.58)$ & $(3.69)$ & $(4.33)$ & $(5.35)$ & $(6.45)$ & $(1.86)$ \\
\hline
\end{tabular}


Table 3

Fama-MacBeth Cross-Sectional Regressions

We report results from Fama-MacBeth cross-sectional regressions of weekly stock returns (in bps) on firm characteristics for the period January 1993 to September 2008. Firm characteristics are Realized Volatility, Realized Skewness, Realized Kurtosis, Size (market capitalization in \$billions), BE/ME (book-to-market equity ratio), Market Beta, Lagged Return (in bps), Historical Skewness (one month historical skewness from daily returns), Idiosyncratic Volatility (computed as in Ang, Hodrick, Xing, and Zhang (2006)), Coskewness (computed as in Harvey and Siddique (2000) with 24 months of data), Maximum Return of previous month in bps, Maximum Return of previous week in bps, Number of Analysts (from I/B/E/S), Illiquidity (annual average of the absolute return over daily dollar trading volume times $10^{6}$, as in Amihud (2002)), and Number of Intraday Transactions. We report the average of the coefficient estimates for the weekly regressions along with the Newey-West t-statistic (in parentheses).

\begin{tabular}{|c|c|c|c|c|c|}
\hline & $(1)$ & $(2)$ & $(3)$ & $(4)$ & $(5)$ \\
\hline Intercept & $\begin{array}{c}26.6 \\
(3.63)\end{array}$ & $\begin{array}{c}31.6 \\
(3.25)\end{array}$ & $\begin{array}{c}21.2 \\
(2.02)\end{array}$ & $\begin{array}{c}19.9 \\
(2.42)\end{array}$ & $\begin{array}{l}180.5 \\
(6.85)\end{array}$ \\
\hline Realized Volatility & $\begin{array}{c}5.9 \\
(0.43)\end{array}$ & & & $\begin{array}{c}2.7 \\
(0.19)\end{array}$ & $\begin{array}{c}3.7 \\
(0.45)\end{array}$ \\
\hline Realized Skewness & & $\begin{array}{c}-22.4 \\
(-7.92)\end{array}$ & & $\begin{array}{c}-24.3 \\
(-9.20)\end{array}$ & $\begin{array}{c}-12.7 \\
(-6.90)\end{array}$ \\
\hline Realized Kurtosis & & & $\begin{array}{c}1.25 \\
(3.39)\end{array}$ & $\begin{array}{c}1.22 \\
(2.86)\end{array}$ & $\begin{array}{c}0.61 \\
(1.91)\end{array}$ \\
\hline $\log ($ Size $)$ & & & & & $\begin{array}{l}-12.8 \\
(-5.53)\end{array}$ \\
\hline $\log (\mathrm{BE} / \mathrm{ME})$ & & & & & $\begin{array}{c}3.0 \\
(1.80)\end{array}$ \\
\hline Market Beta & & & & & $\begin{array}{c}-7.1 \\
(-1.06)\end{array}$ \\
\hline Lagged Return & & & & & $\begin{array}{l}-0.026 \\
(-9.34)\end{array}$ \\
\hline Historical Skewness & & & & & $\begin{array}{c}17.6 \\
(9.77)\end{array}$ \\
\hline Idiosyncratic Volatility & & & & & $\begin{array}{c}26.7 \\
(0.11)\end{array}$ \\
\hline Coskewness & & & & & $\begin{array}{c}16.3 \\
(1.05)\end{array}$ \\
\hline Maximum Monthly Return & & & & & $\begin{array}{l}-0.021 \\
(-3.11)\end{array}$ \\
\hline Maximum Weekly Return & & & & & $\begin{array}{l}-0.019 \\
(-3.96)\end{array}$ \\
\hline $\log ($ Number of Analysts+1) & & & & & $\begin{array}{c}0.47 \\
(0.21)\end{array}$ \\
\hline Illiquidity & & & & & $\begin{array}{c}-13.7 \\
(-0.72)\end{array}$ \\
\hline $\log$ (Number of Intraday transactions) & & & & & $\begin{array}{c}13.4 \\
(5.37)\end{array}$ \\
\hline Adjusted Rsquare & 0.024 & 0.002 & 0.002 & 0.029 & 0.087 \\
\hline
\end{tabular}


Table 4

Drift Adjusted Realized Moments and the Cross-Section of Stock Returns

We report value- and equal-weighted weekly returns (in bps) of decile portfolios formed from drift adjusted realized moments, the corresponding t-statistics (in parentheses), and the return difference between portfolio 10 (highest realized moment) and portfolio 1 (lowest realized moment) over the period January 1993 to September 2008. Panel A displays results for the drift adjusted realized skewness and Panel B for the drift adjusted realized kurtosis. Raw returns (in bps) are obtained from decile portfolios sorted solely from ranking stocks based on the realized moment measure. Alpha is the intercept from time-series regressions of the returns of the portfolio using the Carhart four factor model.

Panel A: Drift Adjusted Realized Skewness

\begin{tabular}{|c|c|c|c|c|c|c|c|c|c|c|c|}
\hline & Low & 2 & 3 & 4 & 5 & 6 & 7 & 8 & 9 & High & High-Low \\
\hline & \multicolumn{11}{|c|}{ Value weighted } \\
\hline \multirow[t]{2}{*}{ Raw Returns } & 34.19 & 24.98 & 23.45 & 16.72 & 22.73 & 19.86 & 22.11 & 17.75 & 12.50 & 20.09 & -14.10 \\
\hline & $(3.72)$ & $(2.56)$ & $(2.49)$ & $(1.80)$ & $(2.44)$ & $(2.15)$ & $(2.47)$ & $(1.97)$ & $(1.40)$ & $(2.35)$ & $(-2.51)$ \\
\hline \multirow[t]{3}{*}{ Alpha, C4 } & 20.66 & 12.05 & 13.59 & 7.63 & 14.71 & 11.13 & 13.28 & 7.70 & 4.07 & 7.75 & -14.57 \\
\hline & $(4.92)$ & $(2.87)$ & $(3.59)$ & $(2.23)$ & $(4.15)$ & $(3.39)$ & $(4.16)$ & $(2.36)$ & $(1.16)$ & $(2.01)$ & $(-2.59)$ \\
\hline & \multicolumn{11}{|c|}{ Equal weighted } \\
\hline \multirow[t]{2}{*}{ Raw Returns } & 48.50 & 37.55 & 32.70 & 28.12 & 26.94 & 25.26 & 24.45 & 23.69 & 19.25 & 18.51 & -29.99 \\
\hline & $(4.54)$ & $(3.47)$ & $(3.06)$ & $(2.69)$ & $(2.62)$ & $(2.53)$ & $(2.49)$ & $(2.39)$ & $(2.01)$ & $(2.04)$ & $(-7.35)$ \\
\hline \multirow[t]{2}{*}{ Alpha, C4 } & 31.08 & 20.42 & 17.16 & 12.80 & 11.96 & 9.73 & 9.41 & 7.83 & 3.57 & 1.80 & -30.94 \\
\hline & $(8.31)$ & $(6.09)$ & $(5.48)$ & $(4.35)$ & $(4.39)$ & $(3.87)$ & $(3.85)$ & $(3.13)$ & (1.41) & $(0.66)$ & $(-8.14)$ \\
\hline
\end{tabular}

Panel B: Drift Adjusted Realized Kurtosis

\begin{tabular}{|c|c|c|c|c|c|c|c|c|c|c|c|}
\hline & Low & 2 & 3 & 4 & 5 & 6 & 7 & 8 & 9 & High & High-Low \\
\hline & \multicolumn{11}{|c|}{ Value weighted } \\
\hline \multirow[t]{2}{*}{ Raw Returns } & 16.93 & 20.30 & 18.54 & 26.63 & 18.81 & 13.49 & 24.11 & 26.10 & 19.58 & 29.52 & 12.60 \\
\hline & $(1.78)$ & $(2.25)$ & $(2.08)$ & $(2.98)$ & $(2.09)$ & $(1.44)$ & $(2.68)$ & $(2.80)$ & $(2.27)$ & $(3.42)$ & $(1.97)$ \\
\hline \multirow[t]{3}{*}{ Alpha, C4 } & 8.46 & 10.84 & 7.11 & 16.29 & 7.89 & 2.08 & 11.52 & 12.97 & 6.42 & 16.08 & 5.96 \\
\hline & $(2.67)$ & $(3.83)$ & $(2.22)$ & $(4.79)$ & $(2.17)$ & $(0.55)$ & $(2.99)$ & $(3.05)$ & $(1.53)$ & $(3.52)$ & $(1.01)$ \\
\hline & \multicolumn{11}{|c|}{ Equal weighted } \\
\hline \multirow[t]{2}{*}{ Raw Returns } & 22.44 & 25.26 & 25.16 & 25.68 & 26.69 & 27.36 & 28.34 & 29.92 & 35.22 & 38.90 & 16.47 \\
\hline & $(2.27)$ & $(2.49)$ & $(2.42)$ & $(2.41)$ & $(2.53)$ & $(2.62)$ & $(2.75)$ & $(2.91)$ & $(3.54)$ & $(4.26)$ & $(3.12)$ \\
\hline \multirow[t]{2}{*}{ Alpha, C4 } & 12.01 & 11.02 & 9.65 & 9.20 & 9.72 & 10.24 & 10.78 & 12.72 & 18.10 & 22.33 & 8.65 \\
\hline & $(4.36)$ & $(4.26)$ & $(3.47)$ & $(3.06)$ & $(3.33)$ & (3.63) & $(3.87)$ & $(4.22)$ & (5.68) & $(6.63)$ & $(2.03)$ \\
\hline
\end{tabular}


Table 5

Fama-MacBeth Cross-Sectional Regressions for Drift Adjusted Realized Moments

We report results from Fama-MacBeth cross-sectional regressions of weekly stock returns (in bps) on firm characteristics for the period January 1993 to September 2008. Firm characteristics are Realized Volatility, Realized Skewness, Realized Kurtosis, Size (market capitalization in \$billions), BE/ME (book-to-market equity ratio), Market Beta, Lagged Return (in bps), Historical Skewness (one month historical skewness from daily returns), Idiosyncratic Volatility (computed as in Ang, Hodrick, Xing, and Zhang (2006)), Coskewness (computed as in Harvey and Siddique (2000) with 24 months of data), Maximum Return of previous month in bps, Maximum Return of previous week in bps, Number of Analysts (from I/B/E/S), Illiquidity (annual average of the absolute return over daily dollar trading volume times $10^{6}$, as in Amihud (2002)), and Number of Intraday Transactions. We report the average of the coefficient estimates for the weekly regressions along with the Newey-West t-statistic (in parentheses).

\begin{tabular}{|c|c|c|c|c|c|}
\hline & (1) & $(2)$ & $(3)$ & $(4)$ & $(5)$ \\
\hline Intercept & $\begin{array}{c}26.5 \\
(3.61)\end{array}$ & $\begin{array}{c}30.9 \\
(3.20)\end{array}$ & $\begin{array}{c}19.7 \\
(1.88)\end{array}$ & $\begin{array}{c}17.9 \\
(2.18)\end{array}$ & $\begin{array}{l}178.1 \\
(6.80)\end{array}$ \\
\hline Realized Volatility & $\begin{array}{c}6.2 \\
(0.45)\end{array}$ & & & $\begin{array}{c}3.3 \\
(0.23)\end{array}$ & $\begin{array}{c}4.8 \\
(0.57)\end{array}$ \\
\hline Realized Skewness & & $\begin{array}{c}-17.5 \\
(-6.82)\end{array}$ & & $\begin{array}{c}-18.5 \\
(-7.88)\end{array}$ & $\begin{array}{l}-11.4 \\
(-6.10)\end{array}$ \\
\hline Realized Kurtosis & & & $\begin{array}{c}1.45 \\
(3.84)\end{array}$ & $\begin{array}{c}1.37 \\
(3.16)\end{array}$ & $\begin{array}{c}0.68 \\
(2.13)\end{array}$ \\
\hline $\log ($ Size $)$ & & & & & $\begin{array}{l}-12.8 \\
(-5.54)\end{array}$ \\
\hline $\log (\mathrm{BE} / \mathrm{ME})$ & & & & & $\begin{array}{c}3.0 \\
(1.78)\end{array}$ \\
\hline Market Beta & & & & & $\begin{array}{c}-7.2 \\
(-1.07)\end{array}$ \\
\hline Lagged Return & & & & & $\begin{array}{l}-0.027 \\
(-9.69)\end{array}$ \\
\hline Historical Skewness & & & & & $\begin{array}{c}17.6 \\
(9.76)\end{array}$ \\
\hline Idiosyncratic Volatility & & & & & $\begin{array}{c}38.0 \\
(0.16)\end{array}$ \\
\hline Coskewness & & & & & $\begin{array}{c}16.3 \\
(1.05)\end{array}$ \\
\hline Maximum Monthly Return & & & & & $\begin{array}{l}-0.021 \\
(-3.07)\end{array}$ \\
\hline Maximum Weekly Return & & & & & $\begin{array}{l}-0.021 \\
(-4.28)\end{array}$ \\
\hline $\log ($ Number of Analysts+1) & & & & & $\begin{array}{c}0.53 \\
(0.24)\end{array}$ \\
\hline Illiquidity & & & & & $\begin{array}{c}-14.1 \\
(-0.74)\end{array}$ \\
\hline $\log$ (Number of Intraday transactions) & & & & & $\begin{array}{c}13.5 \\
(5.42)\end{array}$ \\
\hline Adjusted Rsquare & 0.024 & 0.001 & 0.002 & 0.028 & 0.087 \\
\hline
\end{tabular}


Table 6

Alternative Realized Volatility Estimators, Higher Moments, and the Cross-Section of Stock Returns

We report the value-weighted and equal-weighted weekly returns (in bps) of the difference between portfolio 10 (highest realized moment) and portfolio 1 (lowest realized moment) during January 1993 to September 2008. Stocks are ranked based on their realized moments using different realized volatility estimators. Panel A displays the results for alternative realized volatility estimators, Panel B for realized skewness scaled by alternative realized volatility estimators, and Panel $\mathrm{C}$ for realized kurtosis scaled by alternative realized volatility estimators. Alpha is the intercept from time-series regressions of the returns of the portfolio that buys portfolio 10 and sells portfolio 1 using the Carhart four factor model.

Panel A: Long-Short Returns for Alternative Realized Volatility Estimators

\begin{tabular}{lcccc} 
& RV & BPV & minRV & medRV \\
\hline \multirow{4}{*}{ Raw Returns } & -11.92 & -21.75 & -20.21 & -21.66 \\
& $(-0.65)$ & $(-1.15)$ & $(-1.10)$ & $(-1.18)$ \\
Alpha, C4 & -3.25 & -13.68 & -12.34 & -14.08 \\
& $(-0.29)$ & $(-1.20)$ & $(-1.11)$ & $(-1.25)$ \\
\hline \multirow{4}{c}{ Equal weighted } \\
\hline Raw Returns & 5.08 & 0.39 & -0.26 & 0.14 \\
Alpha, C4 & $(0.33)$ & $(0.02)$ & $(-0.02)$ & $(0.01)$ \\
& 4.48 & 0.22 & 0.05 & 0.05 \\
& $(0.54)$ & $(0.02)$ & $(0.01)$ & $(0.01)$ \\
\hline
\end{tabular}

Panel B: Long-Short Returns for Realized Skewness Scaled by Alternative Realized Volatility Estimators

\begin{tabular}{lcccc}
\hline Realized Skewness scaled by & RV & BPV & minRV & medRV \\
\hline Raw Returns & \multicolumn{5}{c}{ Value weighted } \\
Alpha, C4 & -23.80 & -16.64 & -19.96 & -21.75 \\
& $(-3.65)$ & $(-3.23)$ & $(-3.86)$ & $(-3.72)$ \\
& -24.39 & -19.14 & -22.44 & -24.20 \\
& $(-3.74)$ & $(-3.69)$ & $(-4.32)$ & $(-4.10)$ \\
\hline Raw Returns & -43.44 & -24.31 & -27.29 & -31.22 \\
Alpha, C4 & $(-8.91)$ & $(-7.14)$ & $(-7.95)$ & $(-8.58)$ \\
& -44.49 & -26.18 & -29.00 & -33.00 \\
& $(-9.66)$ & $(-7.91)$ & $(-8.65)$ & $(-9.22)$ \\
\hline
\end{tabular}

Panel C: Long-Short Returns for Realized Kurtosis Scaled by Alternative Realized Volatility Estimators

\begin{tabular}{lcccc}
\hline Realized Kurtosis scaled by & RV & BPV & minRV & medRV \\
\hline Raw Returns & \multicolumn{4}{c}{ Value weighted } \\
& 13.57 & 11.69 & 13.14 & 12.44 \\
Alpha, C4 & $(2.12)$ & $(1.88)$ & $(2.21)$ & $(2.06)$ \\
& 6.85 & 7.39 & 6.09 & 4.90 \\
& $(1.16)$ & $(1.38)$ & $(1.18)$ & $(0.91)$ \\
\hline Raw Returns & 15.77 & 14.69 & 18.13 & 18.54 \\
\multirow{2}{*}{ Alpha, C4 } & $(2.98)$ & $(2.45)$ & $(3.32)$ & $(3.59)$ \\
& 7.97 & 9.28 & 10.81 & 12.04 \\
& $(1.86)$ & $(1.99)$ & $(2.46)$ & $(2.84)$ \\
\hline
\end{tabular}


Table 7

Long-Short Returns for Alternative Skewness Measures

We report the long-short weekly returns computed as in Table 2 for realized skewness and historical skewness measures. Panel A displays realized skewness (RSkew), SubRSkew, the average realized skewness over different subsamples as suggested by Zhang, Mykland, and Ait-Sahalia (2005), SubRSkew drift, the average drift adjusted realized skewness over different subsamples as suggested by Zhang, Mykland, and Ait-Sahalia (2005), and the interquartile skewness $(S K 2)$ defined as $\left(Q_{3}+Q_{1}-2 Q_{2}\right) /\left(Q_{3}-Q_{2}\right)$ where $Q_{i}$ is the $i^{\text {th }}$ quartile of the five-minute return distribution. Panel B displays historical skewness $\left(H S k e w_{t}\right)$ computed with daily returns across different horizons (5 days, 1 month, 6 months, 12 months, 24 months and 60 months). The data sample is from January 1993 to September 2008.

Panel A: Realized Skewness

\begin{tabular}{lcccc}
\hline & RSkew & SubRSkew & SubRSkew drift & SK2 \\
\hline Raw Returns & -23.80 & -47.39 & -18.40 & -7.84 \\
& $(-3.65)$ & $(-5.80)$ & $(-2.74)$ & $(-1.63)$ \\
Alpha, C4 & -24.39 & -51.24 & -21.61 & -10.47 \\
& $(-3.74)$ & $(-6.38)$ & $(-3.24)$ & $(-2.21)$ \\
\hline \multicolumn{5}{c}{ Equal weighted } \\
\hline Raw Returns & -43.44 & -59.64 & -10.16 \\
Alpha, C4 & $(-8.91)$ & $(-8.63)$ & $(-2.06)$ & -11.06 \\
& -44.49 & -61.10 & -9.80 & -13.72 \\
& $(-9.66)$ & $(-9.60)$ & $(-2.32)$ & $(-3.23)$ \\
\hline
\end{tabular}

Panel B: Historical Skewness

\begin{tabular}{|c|c|c|c|c|c|c|}
\hline & HSkew $5 D$ & HSkew $1 M$ & HSkew $_{6 M}$ & HSkew $12 \Lambda$ & ISkew $_{24} M$ & HSkew $60 M$ \\
\hline & \multicolumn{6}{|c|}{ Value weighted } \\
\hline \multirow[t]{2}{*}{$\overline{\text { Raw Returns }}$} & 26.01 & 28.87 & 3.18 & 3.27 & 2.26 & -7.44 \\
\hline & $(4.28)$ & $(4.58)$ & $(0.49)$ & $(0.51)$ & $(0.34)$ & $(-1.00)$ \\
\hline \multirow[t]{3}{*}{ Alpha, C4 } & 23.78 & 31.11 & -0.17 & -3.44 & -3.83 & -12.74 \\
\hline & $(3.89)$ & $(5.08)$ & $(-0.03)$ & $(-0.55)$ & $(-0.61)$ & $(-1.86)$ \\
\hline & \multicolumn{6}{|c|}{ Equal weighted } \\
\hline \multirow[t]{2}{*}{ Raw Returns } & 14.15 & 26.75 & 0.35 & -0.78 & -3.74 & -7.42 \\
\hline & $(3.77)$ & $(5.08)$ & $(0.05)$ & $(-0.11)$ & $(-0.48)$ & $(-0.90)$ \\
\hline \multirow[t]{2}{*}{ Alpha, C4 } & 12.61 & 25.42 & -6.00 & -8.20 & -10.35 & -13.50 \\
\hline & $(3.48)$ & $(5.55)$ & $(-1.14)$ & $(-1.47)$ & $(-1.77)$ & $(-2.25)$ \\
\hline
\end{tabular}


Table 8

Realized Moments and Returns for Different Subsamples

We report weekly returns (in bps) and t-statistics of quintile portfolios formed from ranking stocks by their realized moments. We also report the difference between portfolio 5 (highest realized moment) and portfolio 1 (lowest realized moment). Panel A displays results for realized skewness and Panel B for realized kurtosis. Each panel reports the value- and equal-weighted quintile portfolio returns for the month of January, for all months excluding January, and only for NYSE stocks.

Panel A: Realized Skewness Effects for Different Subsamples

\begin{tabular}{ccccccc}
\cline { 2 - 7 } & \multicolumn{7}{c}{ Value weighted } \\
\cline { 2 - 7 } & Low & 2 & 3 & 4 & High & High-Low \\
\hline Raw Returns, January & 54.76 & 43.49 & 36.75 & 18.08 & 24.20 & -30.57 \\
& $(2.11)$ & $(1.45)$ & $(1.43)$ & $(0.68)$ & $(0.90)$ & $(-1.72)$ \\
Raw Returns, Non-January & 34.31 & 20.93 & 19.47 & 13.99 & 8.09 & -26.22 \\
& $(3.41)$ & $(2.03)$ & $(2.08)$ & $(1.52)$ & $(0.93)$ & $(-4.80)$ \\
Raw Returns, NYSE & 44.61 & 31.23 & 26.48 & 13.90 & 13.06 & -31.55 \\
& $(3.08)$ & $(2.04)$ & $(1.82)$ & $(1.01)$ & $(1.02)$ & $(-3.51)$ \\
\cline { 2 - 7 } & & \multicolumn{5}{c}{} \\
\cline { 2 - 7 } Raw Returns, January & Low & 2 & 3 & 4 & High & High-Low \\
& 93.27 & 55.86 & 59.54 & 54.28 & 37.21 & -56.05 \\
Returns, Non-January & $(2.72)$ & $(1.74)$ & $(1.98)$ & $(1.76)$ & $(1.31)$ & $(-4.13)$ \\
& 46.36 & 31.37 & 22.15 & 17.90 & 10.11 & -36.25 \\
Raw Returns, NYSE & $(4.05)$ & $(2.78)$ & $(2.08)$ & $(1.75)$ & $(1.06)$ & $(-8.36)$ \\
& 66.84 & 44.06 & 28.57 & 18.80 & 2.48 & -64.36 \\
& $(4.81)$ & $(3.08)$ & $(2.06)$ & $(1.40)$ & $(0.21)$ & $(-12.27)$ \\
\hline
\end{tabular}

Panel B: Realized Kurtosis Effects for Different Subsamples

\begin{tabular}{ccccccc}
\cline { 2 - 7 } & \multicolumn{5}{c}{ Value weighted } \\
\cline { 2 - 7 } & Low & 2 & 3 & 4 & High & High-Low \\
\hline Raw Returns, January & 31.25 & 38.43 & 37.81 & 30.27 & 58.70 & 27.44 \\
& $(1.20)$ & $(1.44)$ & $(1.38)$ & $(1.26)$ & $(2.10)$ & $(1.46)$ \\
Raw Returns, Non-January & 17.49 & 21.28 & 13.61 & 23.45 & 19.44 & 1.95 \\
& $(1.82)$ & $(2.35)$ & $(1.45)$ & $(2.51)$ & $(2.24)$ & $(0.39)$ \\
Raw Returns, NYSE & 25.41 & 22.47 & 16.71 & 33.42 & 32.15 & 6.75 \\
& $(1.75)$ & $(1.59)$ & $(1.24)$ & $(2.71)$ & $(2.89)$ & $(0.75)$ \\
\cline { 2 - 7 } & & & & & \\
\cline { 2 - 7 } Raw Returns, January & Low & 2 & 3 & 4 & High & High-Low \\
& $(1.14$ & 58.03 & 63.79 & 60.40 & 70.76 & 23.62 \\
Raw Returns, Non-January & $(1.82)$ & $(1.97)$ & $(1.93)$ & $(2.34)$ & $(1.59)$ \\
& 22.05 & 22.56 & 23.74 & 26.26 & 33.23 & 11.18 \\
Raw Returns, NYSE & $2.10)$ & $(2.05)$ & $(2.16)$ & $(2.44)$ & $(3.35)$ & $(2.66)$ \\
& $(1.63)$ & 31.95 & 28.70 & 33.81 & 40.34 & 14.49 \\
& $(2.16)$ & $(2.11)$ & $(2.67)$ & $(3.72)$ & $(1.88)$ \\
\hline
\end{tabular}


Table 9

Weekly Realized Skewness and the Cross-Section of Monthly Stock Returns

We report the value- and equal-weighted monthly returns (in bps) of decile portfolios formed from realized skewness, their Newey-West t-statistics (in parentheses) and the return difference between portfolio 10 (highest realized moment) and portfolio 1 (lowest realized moment) over the period January 1993 to September 2008. Raw returns (in bps) are obtained from decile portfolios sorted solely from ranking stocks based on the realized skewness measure. Alpha is the intercept from time-series regressions of the returns of the portfolio that buys portfolio 10 and sells portfolio 1 using the Carhart four factor model.

\begin{tabular}{|c|c|c|c|c|c|c|c|c|c|c|c|}
\hline & Low & 2 & 3 & 4 & 5 & 6 & 7 & 8 & 9 & High & High-Low \\
\hline & \multicolumn{11}{|c|}{ Value weighted } \\
\hline \multirow[t]{2}{*}{ Raw Returns } & 112.31 & 84.25 & 81.82 & 83.82 & 89.20 & 66.91 & 71.81 & 64.06 & 64.49 & 77.01 & -35.30 \\
\hline & $(3.77)$ & $(2.80)$ & $(2.78)$ & $(2.86)$ & $(3.09)$ & $(2.47)$ & $(2.52)$ & $(2.33)$ & $(2.54)$ & $(3.10)$ & $(-2.63)$ \\
\hline \multirow[t]{3}{*}{ Alpha, C4 } & 64.74 & 37.87 & 42.20 & 41.91 & 50.16 & 30.07 & 30.14 & 27.26 & 21.75 & 33.39 & -37.96 \\
\hline & $(5.93)$ & $(3.94)$ & $(5.21)$ & $(4.03)$ & $(5.68)$ & $(4.57)$ & $(2.99)$ & $(3.26)$ & $(3.10)$ & $(4.08)$ & $(-2.69)$ \\
\hline & \multicolumn{11}{|c|}{ Equal weighted } \\
\hline \multirow[t]{2}{*}{ Raw Returns } & 128.61 & 114.74 & 102.22 & 96.81 & 102.05 & 86.29 & 97.79 & 84.10 & 84.18 & 88.65 & -39.96 \\
\hline & $(3.37)$ & $(2.97)$ & $(2.72)$ & $(2.66)$ & $(2.82)$ & $(2.49)$ & $(2.86)$ & $(2.47)$ & $(2.54)$ & $(2.80)$ & $(-3.29)$ \\
\hline \multirow[t]{2}{*}{ Alpha, C4 } & 63.30 & 50.16 & 41.76 & 38.28 & 41.86 & 28.27 & 39.65 & 20.52 & 20.34 & 21.72 & -48.20 \\
\hline & $(7.22)$ & $(5.82)$ & $(6.00)$ & $(5.35)$ & $(6.03)$ & $(4.82)$ & $(5.96)$ & $(2.83)$ & $(2.80)$ & $(2.65)$ & $(-4.34)$ \\
\hline
\end{tabular}


Table 10

Double Sorting on Firm Characteristics and Realized Skewness

Stocks are sorted into five quintiles each week based on a given firm characteristic as well as on realized skewness, and 25 portfolios are formed based on these two criteria. We then compute value- and equalweighted average weekly returns of the difference between the highest and lowest skewness portfolio for a given level of the firm characteristic, along with the t-statistic (in parentheses). Firm characteristics are Size (market capitalization in \$billions), BE/ME (book-to-market equity ratio), Realized Volatility (weekly realized volatility computed with high-frequency data), Historical Skewness (one month historical skewness from daily returns), Illiquidity (annual average of the absolute return over daily dollar trading volume times $10^{6}$, as in Amihud (2002)), Number of Intraday Transactions, Maximum Return (of previous month), Number of Analysts (from I/B/E/S), Market Beta, Lagged Return, Idiosyncratic Volatility (computed as in Ang, Hodrick, Xing, and Zhang (2006)) and Coskewness (computed as in Harvey and Siddique (2000)).

\begin{tabular}{|c|c|c|c|c|c|}
\hline \multirow[b]{2}{*}{ Quintiles } & \multicolumn{5}{|c|}{ Value Weighted } \\
\hline & Low & 2 & 3 & 4 & High \\
\hline Size & -74.9 & -37.9 & -29.1 & -8.7 & -28.5 \\
\hline RSkew 5-1 & $(-10.55)$ & $(-6.48)$ & $(-5.57)$ & $(-1.65)$ & $(-4.68)$ \\
\hline $\mathrm{BE} / \mathrm{ME}$ & -51.4 & -34.5 & -20.1 & -1.6 & -10.1 \\
\hline RSkew 5-1 & $(-5.00)$ & $(-4.60)$ & $(-3.00)$ & $(-0.23)$ & $(-1.49)$ \\
\hline Realized Volatility & -25.8 & -27.5 & -25.6 & -33.6 & -58.3 \\
\hline RSkew 5-1 & $(-5.17)$ & $(-3.94)$ & $(-3.00)$ & $(-3.21)$ & $(-4.43)$ \\
\hline Realized Kurtosis & -34.9 & -16.3 & -22.4 & -32.9 & -16.3 \\
\hline RSkew 5-1 & $(-3.11)$ & $(-1.99)$ & $(-3.22)$ & $(-4.58)$ & $(-2.68)$ \\
\hline Historical Skewness & -20.6 & -32.2 & -27.6 & -26.7 & -24.2 \\
\hline RSkew 5-1 & $(-2.77)$ & $(-4.22)$ & $(-3.58)$ & $(-3.11)$ & $(-2.77)$ \\
\hline Illiquidity & -27.7 & -15.4 & -18.7 & -35.0 & -80.3 \\
\hline RSkew 5-1 & $(-4.48)$ & $(-3.12)$ & $(-3.41)$ & $(-5.58)$ & $(-10.54)$ \\
\hline Intra. Transactions & -20.1 & -16.1 & -17.9 & -24.7 & -30.5 \\
\hline RSkew 5-1 & $(-3.92)$ & $(-3.31)$ & $(-3.73)$ & $(-4.82)$ & $(-4.32)$ \\
\hline Maximum Return & -18.4 & -30.3 & -30.3 & -20.3 & -42.1 \\
\hline RSkew 5-1 & $(-2.50)$ & $(-3.57)$ & $(-2.92)$ & $(-1.91)$ & $(-3.38)$ \\
\hline Nb. of Analysts & -26.0 & -32.5 & -24.7 & -17.8 & -33.5 \\
\hline RSkew 5-1 & $(-3.47)$ & $(-5.24)$ & $(-4.54)$ & $(-3.08)$ & $(-5.12)$ \\
\hline Market Beta & -17.9 & -21.3 & -24.9 & -40.8 & -33.8 \\
\hline RSkew 5-1 & $(-3.12)$ & $(-3.80)$ & $(-3.71)$ & $(-5.04)$ & $(-3.07)$ \\
\hline Lagged Return & -22.2 & -11.9 & -16.0 & 1.1 & -23.0 \\
\hline RSkew 5-1 & $(-1.90)$ & $(-1.55)$ & $(-2.19)$ & $(0.14)$ & $(-2.18)$ \\
\hline Idio. Volatility & -14.5 & -27.8 & -36.9 & -46.4 & -44.1 \\
\hline RSkew 5-1 & $(-2.71)$ & $(-4.07)$ & $(-4.37)$ & $(-4.61)$ & $(-3.64)$ \\
\hline Coskewness & -18.6 & -33.6 & -22.5 & -20.9 & -39.7 \\
\hline RSkew 5-1 & $(-2.24)$ & $(-3.68)$ & $(-2.89)$ & $(-2.81)$ & $(-5.43)$ \\
\hline
\end{tabular}

\begin{tabular}{ccccc}
\hline \multicolumn{5}{c}{ Equal Weighted } \\
\hline Low & 2 & 3 & 4 & High \\
\hline-77.4 & -40.1 & -31.3 & -8.3 & -18.9 \\
$(-10.44)$ & $(-6.76)$ & $(-5.95)$ & $(-1.62)$ & $(-3.81)$ \\
-57.6 & -37.1 & -38.3 & -31.7 & -24.5 \\
$(-7.55)$ & $(-6.41)$ & $(-7.02)$ & $(-5.80)$ & $(-4.08)$ \\
-10.9 & -24.7 & -31.7 & -47.9 & -88.1 \\
$(-3.95)$ & $(-6.83)$ & $(-6.35)$ & $(-8.36)$ & $(-10.42)$ \\
-38.4 & -37.0 & -39.7 & -43.0 & -38.2 \\
$(-3.83)$ & $(-5.17)$ & $(-7.20)$ & $(-8.69)$ & $(-8.63)$ \\
-30.7 & -38.1 & -38.8 & -40.2 & -42.2 \\
$(-5.75)$ & $(-7.13)$ & $(-7.36)$ & $(-7.12)$ & $(-6.91)$ \\
-17.5 & -18.3 & -28.7 & -40.8 & -76.0 \\
$(-3.20)$ & $(-3.47)$ & $(-5.63)$ & $(-7.57)$ & $(-12.04)$ \\
-33.6 & -37.1 & -38.8 & -40.8 & -42.9 \\
$(-8.04)$ & $(-7.69)$ & $(-7.05)$ & $(-6.17)$ & $(-5.48)$ \\
-20.4 & -28.1 & -39.0 & -43.7 & -52.3 \\
$(-3.59)$ & $(-4.13)$ & $(-3.52)$ & $(-2.83)$ & $(-3.77)$ \\
-57.0 & -47.3 & -38.7 & -20.2 & -19.5 \\
$(-8.79)$ & $(-8.42)$ & $(-7.32)$ & $(-3.90)$ & $(-3.43)$ \\
-27.7 & -31.6 & -33.3 & -43.6 & -64.8 \\
$(-5.38)$ & $(-7.65)$ & $(-7.05)$ & $(-8.07)$ & $(-9.24)$ \\
-45.2 & -12.7 & -0.1 & -10.6 & -26.9 \\
$(-6.37)$ & $(-2.66)$ & $(-0.02)$ & $(-1.99)$ & $(-4.00)$ \\
-6.2 & -22.0 & -30.8 & -52.5 & -83.1 \\
$(-2.18)$ & $(-6.22)$ & $(-6.38)$ & $(-8.77)$ & $(-10.86)$ \\
-51.9 & -36.6 & -29.9 & -37.0 & -35.1 \\
$(-9.34)$ & $(-6.54)$ & $(-5.76)$ & $(-7.22)$ & $(-6.77)$ \\
\hline & & & &
\end{tabular}


2013-23: $\quad$ Asger Lunde and Anne Floor Brix: Estimating Stochastic Volatility Models using Prediction-based Estimating Functions

2013-24: Nima Nonejad: A Mixture Innovation Heterogeneous Autoregressive Model for Structural Breaks and Long Memory

2013-25: Nima Nonejad: Time-Consistency Problem and the Behavior of US Inflation from 1970 to 2008

2013-26: $\quad$ Nima Nonejad: Long Memory and Structural Breaks in Realized Volatility: An Irreversible Markov Switching Approach

2013-27: $\quad$ Nima Nonejad: Particle Markov Chain Monte Carlo Techniques of Unobserved Compdonent Time Series Models Using Ox

2013-28: $\quad$ Ulrich Hounyo, Sílvia Goncalves and Nour Meddahi: Bootstrapping preaveraged realized volatility under market microstructure noise

2013-29: Jiti Gao, Shin Kanaya, Degui Li and Dag Tjøstheim: Uniform Consistency for Nonparametric Estimators in Null Recurrent Time Series

2013-30: $\quad$ Ulrich Hounyo: Bootstrapping realized volatility and realized beta under a local Gaussianity assumption

2013-31: Nektarios Aslanidis, Charlotte Christiansen and Christos S. Savva: Risk-Return Trade-Off for European Stock Markets

2013-32: Emilio Zanetti Chini: Generalizing smooth transition autoregressions

2013-33: Mark Podolskij and Nakahiro Yoshida: Edgeworth expansion for functionals of continuous diffusion processes

2013-34: Tommaso Proietti and Alessandra Luati: The Exponential Model for the Spectrum of a Time Series: Extensions and Applications

2013-35: Bent Jesper Christensen, Robinson Kruse and Philipp Sibbertsen: A unified framework for testing in the linear regression model under unknown order of fractional integration

2013-36: Niels S. Hansen and Asger Lunde: Analyzing Oil Futures with a Dynamic Nelson-Siegel Model

2013-37: Charlotte Christiansen: Classifying Returns as Extreme: European Stock and Bond Markets

2013-38: $\quad$ Christian Bender, Mikko S. Pakkanen and Hasanjan Sayit: Sticky continuous processes have consistent price systems

2013-39: Juan Carlos Parra-Alvarez: A comparison of numerical methods for the solution of continuous-time DSGE models

2013-40: Daniel Ventosa-Santaulària and Carlos Vladimir Rodríguez-Caballero: Polynomial Regressions and Nonsense Inference

2013-41: Diego Amaya, Peter Christoffersen, Kris Jacobs and Aurelio Vasquez: Does Realized Skewness Predict the Cross-Section of Equity Returns? 